\title{
El agotamiento del derecho de distribución y su aplicación en un entorno digital
}

\author{
The First Sale Theory of the Right of Distribution \\ and its Application in a Digital Environment
}

\author{
JAVIERA PLANA PERILLÁN \\ Abogada independiente, Chile
}

RESUMEN La teoría del agotamiento del derecho permite el acceso masivo al público de las obras protegidas por el derecho de autor. Con la llegada de internet, la implementación de esta teoría y sus efectos tradicionales se ponen en duda, por lo que resulta necesario revisar los alcances y condiciones de aplicación del agotamiento, con el fin de poder determinar si es factible o no adaptarla al entorno digital. En la siguiente investigación la autora aborda este conflicto, revisando el contexto en el que se envuelve el agotamiento del derecho de distribución, así como los principales obstáculos que surgen con el cambio del entorno digital. Finalmente, argumenta que es posible implementar una teoría del agotamiento en internet.

PALABRAS CLAVE Teoría del agotamiento del derecho, derechos de autor, derecho de distribución, derecho de reproducción.

ABSTRACT The first sale theory allows the massive entry to the public of works protected by copyright. With the uptake of the internet, the implementation of this theory, as well as their traditional effects are put in doubt, so it is necessary to review the scope and conditions of application 
of the exhaustion, to determine if it is feasible or not to adapt it to the digital environment. In this research the author approach this conflict, reviewing the context in which the exhaustion of the right of distribution involves and the main obstacles that arise with the change of the digital environment. Finally, she argues that it is possible to implement a theory of the exhaustion on the internet.

KEYWORDS First sale theory, copyright, right of reproduction, right of distribution.

\section{INTRODUCCIÓN}

En este artículo describiremos los principales obstáculos que se presentan a la hora de implementar la teoría del agotamiento del derecho de distribución de una obra en internet. En ese sentido, presentaremos los temas que constituyen un impedimento a la aplicación del agotamiento en un entorno digital, prescindiendo para su selección del carácter legal, contractual o de otra índole que estos temas puedan presentar, pues lo relevante será el hecho de que afecten o modifiquen el escenario tradicional de aplicación del agotamiento del derecho de distribución.

En consecuencia, el análisis de esta sección necesariamente tendrá que traspasar la visión de lo estrictamente jurídico, y entrar a revisar las limitaciones que surgen en la práctica. Asimismo, cabe hacer presente que, para la identificación de estos impedimentos, traspasaremos la frontera nacional ya que muchas de las dificultades identificadas son temas que han sido desarrollados principalmente en otros ordenamientos jurídicos. Las discusiones desarrolladas en estos ordenamientos tienen o tendrán repercusión en los sistemas de protección de derecho de autor de otros países y por este motivo nos parece pertinente y relevante incluirlos como argumentos centrales de la discusión.

En definitiva, en este artículo buscaremos dar respuesta a la pregunta principal que motiva esta investigación, respecto a si es posible aplicar el agotamiento del derecho de distribución en un entorno digital. 


\section{ALGUNAS CONSIDERACIONES INICIALES}

Para comenzar a entender el conflicto jurídico que nos convoca, de lo primero que debemos ocuparnos es de determinar en qué consiste la teoría de agotamiento del derecho, y, en general, revisar cuáles son sus principales efectos y alcances generales.

En cuanto a su conceptualización, de la revisión de distintos trabajos que la doctrina y jurisprudencia han desarrollado ${ }^{\mathrm{T}}$ podemos definir la teoría del agotamiento del derecho como aquella en virtud de la cual una obra, o más bien una copia de ella, puede circular libre dentro del mercado, producto de la introducción de ésta al comercio. Decidimos reformular este concepto en torno a la libertad de la obra más que al titular del derecho en sí, pues queremos destacar el aporte de la teoría del agotamiento del derecho - facilitar el acceso de las distintas obras intelectuales al público- antes que sólo enfocarnos en la pérdida de un derecho para el titular del derecho de autor.

\section{ANÁLISIS ECONÓMICO DE LA TEORÍA DEL AGOTAMIENTO}

Sabemos que el agotamiento del derecho produce sus efectos en virtud de un acto clave, que es la introducción de bienes protegidos al mercado. ¿Cuáles son los principales efectos que produce en el mercado mismo la teoría del agotamiento del derecho?

Para responder esta pregunta nos basaremos especialmente en la obra del autor estadounidense Anthony Reese que se titula The First Sale Doctrine in the Era of Digital Networks. En este trabajo, escrito a ini-

I. Para Juan David Castro, el agotamiento del derecho de propiedad intelectual «significa que el derecho exclusivo del que goza un titular de un derecho de propiedad intelectual termina en el momento en que él introduce (o permite introducir) en el comercio productos o bienes que están protegidos por dicho derecho" (Castro, 2009: 256); por otro lado, Carmen Paz Álvarez nos explica la teoría del agotamiento en función de las marcas, aportando los elementos fundamentales de la teoría (que resultan aplicables también a los derechos de autor): «El agotamiento de los derechos de marca es el efecto que se produce cuando un titular de la marca, por sí o a través de tercero que obra con su consentimiento, introduce en el comercio un producto protegido con dicha marca, perdiendo por ello la facultad de impedir ulteriormente, sobre la base de los derechos exclusivos que emanan de esa marca, que el producto circule libremente en el mercado» (Álvarez, 2006: 336). 
cios de la década del 2000, el autor hace una estimación de las posibles repercusiones del fenómeno de la masificación de internet, en particular lo que ocurre respecto a la aplicación de la First Sale Doctrine. Para los fines de nuestra investigación, rescatamos el análisis económico que desarrolla dicho artículo, en cuanto identifica y explica con agudeza los principales efectos que tiene el agotamiento del derecho en el mercado.

Según el autor, los principales efectos o aportes de la doctrina de la primera venta son la asequibilidad y la disponibilidad (Reese, 2003: 578; Perzanowski y Schulz, 2010: 894-897), efectos que, en términos simples, facilitarán el acceso a las obras por parte de la audiencia. ${ }^{2}$

En primer lugar, respecto de la asequibilidad, Reese la subdivide en diversos efectos, a saber: la competencia de precios en ventas al por menor, las ventas en mercados secundarios, los mercados de alquiler y los préstamos al público (Reese, 2003: 585-590).

Como primer efecto, entonces, tenemos la competencia de precios, que constituye la manifestación más clara del aumento de la asequibilidad de las obras al público. Como lo explica Reese: "La manera en que la doctrina de la primera venta produce este efecto [asequibilidad] de manera más directa es al permitir la competencia de precios al por menor, donde los propietarios venden sus copias a través de diversos minoristas» (Reese, 2003: 585; ésta y el resto de las traducciones en este artículo son nuestras). La competencia de precios es el efecto más evidente de la doctrina de la primera venta, pues la libertad que entrega el agotamiento se traduce en una serie de usos que van desde el uso privado que puede darle un usuario, hasta la reventa de la obra (la reventa de una obra no tendría sentido si no se le permitiera al revendedor tener libertad para escoger el precio de lo que intenta vender).

Como segundo efecto de la asequibilidad el agotamiento del derecho permite el desarrollo de mercados de «segunda mano». Estos mercados

2. Reese identifica tres principales efectos beneficiosos de la doctrina de la primera venta para el acceso público de las obras protegidas por derecho de autor. Dos de esos efectos son la asequibilidad y la disponibilidad de las obras. El tercer efecto dice relación con permitir a los usuarios el acceso a las obras protegidas, al mismo tiempo que les permite mantener la privacidad o anonimato respecto al dueño del derecho de autor, por el uso de sus obras. Respecto a este tercer efecto del agotamiento del derecho nos referiremos más adelante (2003: 584). 
aumentan la asequibilidad de las obras, pues con su creación disminuyen la presión sobre los precios establecidos por los titulares del derecho de autor (Perzanowski y Schulz, 20I0: 894). Lo importante de este tipo de mercados es que permite a los usuarios encontrar copias de las obras que les interesa a precios mucho más asequibles que los que encontrarían si compraran de primera mano al titular del derecho de autor o al primer minorista (Reese, 2003: 586). Así, tenemos que la doctrina de la primera venta permite la creación de mercados donde las obras pueden ser encontradas a precios mucho más asequibles, creando instancias, $\mathrm{u}$ opciones de venta para los distintos tipos de usuarios, aquellos que están dispuestos a pagar más por una copia nueva, y aquellos que están dispuestos a pagar menos por una copia un poco más gastada.

Luego, como tercer efecto de la asequibilidad, tenemos los mercados de alquiler como otro beneficio obtenido gracias al agotamiento del derecho. Este tipo de mercados está pensado para aquellos que están dispuestos a pagar por tener acceso a una obra protegida por derecho de autor, pero no un precio tan alto como para adquirir el dominio de la copia (Reese, 2003: 587).

Finalmente, otro efecto de la asequibilidad son los préstamos públicos, los que Reese reconoce como el efecto final que reduce los costos de acceso a las obras protegidas por derechos de autor. Tal como explica el autor, es gracias a los efectos de la teoría del agotamiento del derecho que las bibliotecas pueden adquirir copias de bienes protegidos por el derecho de autor, como libros y películas, para luego prestarlas a sus clientes sin ningún cargo o permiso especial (Reese, 2003: 588). Otra manera de disminuir el costo de acceso a las obras protegidas es permitiendo a los usuarios consultar las obras sin necesidad de comprar la obra, como ocurre en el caso de las bibliotecas, las que no requieren obtener una licencia de distribución para prestar sus copias (Reese, 2003: 589).

El segundo efecto o aporte principal que produce la teoría del agotamiento es el de la disponibilidad de las obras y se traduce en que las obras protegidas por derecho de autor se mantienen circulando en el mercado, disponibles al acceso del público aún cuando pase el tiempo, sin preocuparse de los precios (Reese, 2003: 592).

Para el análisis de este efecto de disponibilidad, Reese identifica dos niveles o dimensiones en que podemos encontrar sus consecuencias (Reese, 2003: 592). La primera dimensión se refiere a situaciones en que 
el propio dueño del derecho de autor deja de hacer disponible su obra, ya sea temporalmente o de manera definitiva; y la segunda, se refiere a que el agotamiento del derecho facilita el acceso a las obras protegidas, en cuanto permite la preservación de las obras y su sobrevivencia con el paso del tiempo (Perzanowski y Schulz, 2010: 895; Reese, 2003: 592).

Respecto de la primera dimensión se debe destacar que el agotamiento del derecho juega un rol de equilibrio en el mercado de las obras protegidas, que consiste justamente en compatibilizar los intereses del autor de no continuar con la distribución de una obra y, por otro lado, con el interés general de la sociedad de poder acceder a estas obras intelectuales. Si un autor no quiere que su obra siga siendo difundida, está en todo su derecho a detener ese proceso. Pero a cambio debe asumir que las copias respecto de las cuales ya dio su consentimiento no podrán ser controladas y, por lo tanto, son de libre acceso para aquellos que quieran adquirir o conocer dichos ejemplares. La doctrina de la primera venta opera como una mediación entre los intereses de ambas partes, del autor y de la audiencia (Reese, 2003: 60I).

Hay una distinción importante que se debe hacer: si por razones comerciales o personales del autor se decidiera a dejar de producir una obra, eso no significa que el público pierda interés en ella. Esta distinción es especialmente importante cuando hay cese de distribución por razones comerciales; hay que entender que aun cuando la producción de una obra deje de ser rentable para el titular del derecho de autor, ello no significa que se haya perdido el interés total por dicha obra. Al final, el interés que puede llegar a tener el público por una obra no dice relación necesariamente con la rentabilidad del producto comercial. A veces entran en juego otros factores en contra de ella, como por ejemplo los altos precios del producto, pero ello no debe hacernos entender que el público no desee tener acceso a la obra. En consecuencia, en la medida en que este interés continúe, es que el rol del agotamiento del derecho tiene sentido.

Como segunda dimensión del efecto de disponibilidad de las obras tenemos la preservación en el tiempo. Reese plantea que, en general, la distribución de copias de las obras protegidas por derecho de autor ayuda a la preservación de las obras a lo largo del tiempo (Reese, 2003: 603). Más aún, mientras más copias de una obra se distribuyan, mayor probabilidad de que esta obra se preserve en el tiempo. En este contexto 
es que el agotamiento del derecho juega un rol clave, en cuanto genera y favorece condiciones que colaboran a esta tarea de preservación. En particular, facilita la creación y el desarrollo de bibliotecas (Reese, 2003: 607), una de las principales responsables de llevar adelante la tarea de preservación de las obras; permite la libre circulación de ejemplares de las obras a preservar (Reese, 2003: 607), lo cual ayuda a la preservación, ya que mientras más obras protegidas se encuentren en manos de usuarios, más probabilidades habrá de que se preserven en el tiempo; y, por último, de acuerdo a lo que plantea Reese, hay que tener en cuenta también que si no fuera por la doctrina de la primera venta, muchas copias desaparecerían (Reese, 2003: 607), en cuanto hay una gran cantidad de usuarios que con el tiempo dejan de tener interés en las obras, y en la medida que no tuvieran la posibilidad de prestarlas o revenderlas, simplemente las dejarían abandonadas y con el tiempo se perderían. Considerando que las obras protegidas por derecho de autor constituyen una porción importante de la cultura, esta preservación de las obras beneficia no sólo a los interesados directamente en una obra particular, sino que a toda la sociedad (Perzanowski y Schulz, 2010: 895).

Estos son los principales efectos del agotamiento asociados a la preservación de las obras. No obstante ello, debemos hacer mención de que lo recién expuesto es en un contexto sin internet ni nuevas tecnologías, contexto en el cual la preservación de las obras pasa a ser mucho más sencillo y eficiente. A diferencia de lo que plantea Reese (Reese, 2003: 635), con las nuevas tecnologías la preservación de obras protegidas es más fácil y se logra de mejor manera; por lo tanto, nos parece que en el sentido «clásico» en que se considera este beneficio como propio del agotamiento, pierde un poco de relevancia, pues el medio tecnológico pasa a encargarse de esta tarea de manera mucho más eficiente. Lo anterior, en ningún caso quiere decir que el agotamiento del derecho ha perdido relevancia. Al contrario, durante este capítulo hemos descrito una serie de hechos que dejan en evidencia la relevancia de esta doctrina en la vida cotidiana.

\section{ANÁLISIS JURÍDICO DE LA TEORÍA DEL AGOTAMIENTO}

Respecto de este punto, existen dos asuntos relevantes que debemos revisar. Uno de estos temas es la privacidad; el otro es la distinción entre 
el derecho de autor que protege una obra y el soporte material que la contiene.

Respecto de la privacidad, lo primero que diremos es que es uno de los principales beneficios de la teoría del agotamiento del derecho (Perzanowski y Schulz, 2010: 896; Reese, 2003: 584; Grunewaldt, 20I I: $4)$. Esto debido a que gracias a los efectos del agotamiento, las personas pueden transferir o, en general, disponer de las obras sin necesidad de solicitar autorización al titular del derecho de autor, permitiéndoles hacerlo de manera privada y anónima (Perzanowski y Schulz, 20ıо: 896). A simple vista puede sonar como un efecto secundario o de menor importancia. Sin embargo, si pensáramos un momento en las consecuencias que tendría el hecho de que los autores pudieran controlar sin límites el uso de sus obras, enseguida nos daríamos cuenta de los perjudiciales efectos que ello tendría para la protección de la privacidad y la intimidad de la persona, cuestiones que son esenciales para alcanzar el pleno desarrollo individual; razón por la cual la intimidad, como instrumento fundamental para el impulso de la libertad individual y el respeto de la dignidad humana, constituye un notable beneficio de la teoría del agotamiento.

En relación a esta materia, encontramos pertinente mencionar el artículo de Julie Cohen, "A right to read anonymously: a closer look at 'copyright management' in cyberspace», donde sostiene que «leer es una dimensión importante del derecho individual de libertad asociativa [...] leer es asociación intelectual, pura y simple» (Cohen, I995: 35-36). Este artículo reconoce que, en nuestra sociedad, las personas tienen garantizada la libertad para formar sus pensamientos y opiniones en privado, libres de la intrusión del gobierno y entidades privadas; y a partir de esta base, a modo de tesis central, plantea que respecto de esta libertad para formar opiniones, las actividades de leer, pensar y hablar son igualmente importantes (Cohen, I995: 2). En tal sentido, es relevante cómo la autora rescata el rol que juega la lectura y la libre elección de lo que leemos -elección y actividad que se desarrollan en privado, libre de la influencia de terceros- para la formación de nuestras opiniones (Cohen, I995:36), posicionando la actividad a un mismo nivel que la actividad del discurso y del pensamiento.

Siempre ha habido mayor preocupación por proteger a los hablantes, antes que a los lectores (Cohen, I995: 22), debido quizás a que la lectura 
anónima es un «derecho» que en general siempre se ha considerado garantizado (Cohen, I 995: 34). Sin embargo, la actividad de la lectura, tal cual lo explicita Cohen, es fundamental en el desarrollo de las personas. Es una actividad que debe desarrollarse libremente, en privado, sin la intromisión de terceros.

La teoría del agotamiento del derecho contribuye al desarrollo de esta actividad al permitir la libertad de los consumidores para disponer de sus obras, favoreciendo la libre circulación de las obras sin el control de un tercero que pueda disponer qué obras se pueden prestar o revender, y cuáles no. Esta teoría permite una especie de derecho a leer, a mirar o a escuchar de manera anónima (Gasser y otros, 2004: 52), generando así la privacidad necesaria para el pleno desarrollo de las personas con respecto al uso de las obras protegidas.

Pasemos a revisar ahora el ámbito de aplicación material de la teoría del agotamiento del derecho. Para ello, debemos tener presente dos principios relacionados con la base de esta teoría: la distinción entre la obra protegida y el soporte material que la contiene, y la libre enajenación de los bienes muebles (Perzanowski y Schulz, 2010: 895).

El primer principio se refiere a que el dueño de la copia de una obra es distinto del titular del derecho de autor y, por lo tanto, cualquier transferencia que se haga del objeto material que contiene la obra no implica que haya una transferencia de los derechos de autor de la obra contenida en aquel. ${ }^{3}$ Es la obra, el trabajo intelectual del autor el objeto de protección del derecho de autor, no el objeto material que la contiene (Perzanowski y Schulz, 20I0: 90I).

Este principio se encuentra latente en la teoría del agotamiento del derecho, ya que para definir sus efectos jurídicos es necesario hacer esta distinción. Cuando decimos que con la primera venta se agota el derecho de la copia, nos estamos refiriendo a la copia específica de la cual es propietario el usuario. Y en tal sentido entendemos que los derechos que adquiere este último, en virtud del agotamiento, son respecto de la copia

3. «Si, por ejemplo, el novio dirige una carta a su novia, la propiedad en el papel sobre el cual la carta está escrita pertenece a la destinataria, pero el derecho de autor en el trabajo literario permanece en el novio. La novia como propietaria del papel podrá destruirlo o mostrarlo a otras personas, pero no está facultada, sin autorización, para reproducir la carta» (Rengifo, I997: I05). Véase también Grunewaldt (20II: 4). 
particular. La protección de la obra misma, los derechos que la protegen, se mantienen intactos tras el accionar del agotamiento.

El segundo principio, respecto a la libre circulación de los bienes, dice relación con cierta coherencia del sistema de protección del derecho de autor con el marco mayor en que se encuentra inmerso. La teoría del agotamiento del derecho es la respuesta del derecho de autor frente al principio general de la libre circulación de bienes. ${ }^{4}$

\section{EL ESCENARIO ACTUAL}

Como reconocimos al comienzo de este artículo, es inevitable caer en la revisión de lo que ocurre fuera de nuestras fronteras para comprender el actual escenario en que nos encontramos en la materia, así como asimilar las reales dificultades que enfrentamos para la asimilación del agotamiento del derecho en un entorno digital.

Para ello es necesario revisar el Tratado de la OMPI sobre derecho

4. Este principio impregna nuestro ordenamiento jurídico, sobrepasando las barreras del derecho de autor. Manifestación de ello es el mensaje de nuestro Código Civil enviado por el presidente Manuel Montt al Congreso proponiendo la aprobación del Código redactado por Andrés Bello. Este texto, que data del año I 855 , menciona la importancia de la introducción de modificaciones en materia de fideicomiso y nacimiento y extinción de la personalidad al favorecer la libre circulación de los bienes. Sobre este último tema se refiere la siguiente cita: «En general, se ha disminuido el tiempo de la posesión provisoria en los bienes del desaparecido. Las posesiones provisorias embarazan la circulación y mejora de los bienes y no deben durar más que lo necesario para proteger racionalmente los derechos privados que puedan hallarse en conflicto con los intereses generales de la sociedad. [...] [L]a facilidad y rapidez de las comunicaciones entre países distantes, se han aumentado inmensamente en nuestros días, y ha crecido en la misma proporción la probabilidad de que una persona de quien por mucho tiempo no se ha tenido noticia en el centro de sus relaciones de familia y de sus intereses, o ha dejado de existir, o ha querido cortar los vínculos que la ligaban a su domicilio anterior». (Vale destacar el optimismo respecto a la rapidez de las comunicaciones existente en pleno siglo XIX.) Luego se refiere a los fideicomisos y dice: «Es una regla fundamental en este proyecto la que prohíbe dos o más usufructos o fideicomisos sucesivos, porque unos y otros embarazan la circulación y entibian el espíritu de conservación y mejora, que da vida y movimiento a la industria.» Llama la atención que siendo un principio que inspira diversas normas del proyecto de Código Civil (así como diversas normas de nuestro ordenamiento), su reconocimiento y protección no se cuestiona en ningún momento del texto. Ello manifiesta su carácter de pilar y principio rector de nuestro ordenamiento jurídico. 
de autor, instrumento que surgió justamente para dar respuesta a los grandes cambios tecnológicos y comerciales que comenzaban a gestarse en torno al derecho de autor.

En general, este tratado se ocupa de establecer el alcance de los derechos de autor aplicados en el medio digital, otorga seguridad jurídica al desarrollo del comercio electrónico y aclara las normas existentes, a la vez que crea nuevas normas con miras a dar respuestas a las problemáticas surgidas por el desarrollo de la tecnología digital (Fernández, 2005: 5; OMPI, I999: I7).

Respecto de la materia que nos interesa, este tratado hace importantes aportes, pues reconoce por primera vez de manera expresa y en términos generales la existencia del derecho de distribución y de la teoría del agotamiento del derecho. Sin embargo, también hay que notar que pese a dicho reconocimiento la disposición no juega un rol decisivo en el sentido que entrega una amplia libertad a los Estados para que ellos regulen la materia. Así lo expresa la Guía de los tratados de derecho de autor y derechos conexos administrados por la OMPI:

[El] problema verdaderamente espinoso que plantea el derecho de distribución es su agotamiento al finalizar la primera venta de ejemplares y, en particular, el efecto territorial de dicho agotamiento. Durante la labor de preparación del WTC [Tratado de Derecho de Autor de la OMPI] se intentó reconocer su efecto nacional/regional [...]. Sin embargo esos intentos fueron fallidos y la cuestión del agotamiento, así como su efecto territorial, se dejaron a la total discreción del legislador nacional (Ficsor, 2003: 207).

Esta libertad en la regulación del agotamiento permite la existencia de diversos sistemas, los cuales son adoptados por los distintos países y condicionados principalmente por razones económicas y políticas. ${ }^{5}$ Existen tres sistemas de agotamiento del derecho:

Sistema de agotamiento internacional: Es aquel en el cual los derechos de distribución se agotan una vez que el producto ha sido vendido por el titular del derecho, o con su consentimiento, en cualquier país del

5. "Con independencia de que sea regional o internacional, el agotamiento no es un problema estrictamente jurídico, pues está vinculado en muchos aspectos a la política y la competencia en el plano mundial o regional» (Gaubiac, 2002: 3). 
mundo (Álvarez, 2006: 337). Este sistema de agotamiento del derecho es recogido en distintos países del mundo, como Australia, Nueva Zelanda (Bonadio, 20I I: I 58) y Chile (Cerda, 20II: 25I).

El efecto principal del sistema de agotamiento internacional es que el titular del derecho, una vez que introduce en el mercado un producto protegido, no puede oponerse a ventas futuras de estos productos, independiente del país en que haya sido hecha esta introducción. Este efecto produce las denominadas «importaciones paralelas», las cuales acarrean una serie de consecuencias que implican fuertes impactos en el desarrollo de los mercados internacionales (Bonadio, 20I I: I 54), al favorecer la competencia a nivel de mercados internacionales y el desarrollo de mercados internos.

Sistema de agotamiento nacional: Consiste en que el derecho de distribución exclusivo otorgado a una obra protegida se agota cuando el producto es puesto en circulación con autorización de su titular en el mercado nacional, conservando intacto su derecho de distribución en países extranjeros (Castro, 2009: 260). Es el régimen más restrictivo desde el punto de vista de la libre circulación de bienes (Castro, 2009: 260), en cuanto deja a salvo el derecho de un titular para oponerse a la importación paralela de copias de su obra comercializadas por primera vez en el extranjero por un titular o un tercero con su consentimiento (Álvarez, 2006: 337). Este poder de oposición se traduce, en la práctica, en la segregación de los mercados internacionales (Bonadio, 20 I I: I 54), al permitir un mayor control sobre los precios en los distintos países en que es introducida la obra.

Sistema de agotamiento regional: Es aquel en que el agotamiento se produce cuando el titular de los derechos, o un tercero con su consentimiento, realiza la primera venta del producto en una región determinada (en una comunidad de Estados) (Álvarez, 2006: 337 ).

Se dice que el agotamiento regional es una solución intermedia, que es adoptada generalmente por un conjunto de Estados que forman parte de un mercado común o una unión (Bonadio, 20I I: I 54). En palabras de Enrico Bonadio, el agotamiento regional es un agotamiento internacional «on a small scale» (Bonadio, 20II: I 59). En tal sentido, es que dentro de esta comunidad de países se producen los efectos identificados en el caso del agotamiento internacional, relacionados con las importaciones paralelas, mas no ocurre lo mismo respecto a terceros países, que no forman parte de la comunidad. 
La Unión Europea (UE) se rige por este sistema regional de agotamiento del derecho.

Como podemos ver, las diferencias entre uno y otro sistema de agotamiento son complejas e implican consecuencias que escapan de lo estrictamente jurídico. Fueron justamente estas diferencias las que dificultaron y en definitiva impidieron que se adoptara un sistema común de agotamiento del derecho durante la tramitación del Tratado de la OMPI.

Otro punto importante que menciona el Tratado es la declaración concertada respecto a los artículos 6 y 7. ¿Qué alcances tiene esta declaración? O más bien, ¿qué consecuencias acarrea? De acuerdo a la Guía de los tratados de derecho de autor y derechos conexos administrados por la OMPI esta declaración indica el nivel mínimo de protección, en virtud de lo cual no estaría limitando que se regule un derecho de mayor alcance a lo que se establece en la declaración concertada. Y lo más importante: significa que «se puede extender el derecho de distribución a la distribución a través de la reproducción mediante transmisión» (Ficsor, 2003: 207). Además de esto, está también la denominada solución marco o umbrella solution, que se refiere a la protección de obras y su transmisión por internet.

Durante las negociaciones de este Tratado se discutió acerca de la necesidad de dar protección a las obras que fueran transmitidas por internet, a través de un derecho exclusivo que se le otorgara al autor (Fernández, 2005: 7). Sin embargo, había desacuerdo entre los Estados respecto a qué derecho específico debía aplicarse. Las principales opciones eran el derecho de comunicación al público -impulsado principalmente por la Comunidad Europea y los países latinoamericanos- y el derecho de distribución (Antequera, 2005: I7). El principal impedimento para llegar a un acuerdo fue que los ámbitos de aplicación de uno y otro derecho eran muy distintos en las legislaciones nacionales de los países en negociación (Fernández, 2005: 7). Además, ninguno de los dos derechos propuestos tenía una protección plena en el Convenio de Berna. Más aun, era difícil pensar en aplicar alguno de estos conceptos tradicionales sin realizar aclaraciones previas. En particular respecto del derecho de distribución, habría que especificar que la distribución por medio de la trasmisión digital también queda comprendida dentro del concepto de distribución. Lo mismo ocurría respecto del derecho de comunicación al público (Ficsor, 2003: 213). 
Finalmente, se optó por una solución específica:

que el acto de transmisión digital se describiera de forma neutral, sin una tipificación jurídica específica que estableciera, por ejemplo, cuál de los dos derechos 'tradicionales' mencionados ampara este acto; que tal descripción fuera específicamente tecnológica [...]; que respecto de la tipificación jurídica del derecho exclusivo [...] se otorgase libertad suficiente a la legislación nacional; y, por último, que las deficiencias existentes en el Convenio de Berna en cuanto al alcance de los derechos pertinentes [...] se subsanen. Esta solución se denominó 'solución marco' (OMPI, I996: 8).

Esta solución marco fue incorporada en el artículo 8 del Tratado. Lo importante es que el derecho de comunicación pública reconocido en este artículo, entrega la libertad necesaria a los Estados para escoger la tipificación legal del derecho exclusivo que ellos prefieran, sea el derecho de comunicación pública, o un derecho de distribución por transmisión, o incluso mediante una combinación de derechos (Antequera, 2005: I 8).

Además del Tratado de la OMPI sobre el Derecho de Autor, nos parece necesario revisar la legislación de Estados Unidos, que resulta de gran importancia para comprender las principales tendencias en torno a la adaptación del derecho de autor a las nuevas tecnologías. ${ }^{6}$

Respecto de esta materia, encontramos en la legislación estadounidense dos cuerpos normativos relevantes: la I976 Copyright Act, y la Digital Millenium Copyright Act. La primera contiene los principios y normas esenciales que regulan el copyright, entre ellos el derecho de distribución y su consiguiente agotamiento; la segunda es una ley más reciente, que fue dictada con el fin de implementar los Tratados de la OMPI de I996, y que resulta importante revisar en cuanto es necesaria para comprender uno de los principales impedimentos de la aplicación de la first sale doctrine en un entorno digital.

La Copyright Act regula el derecho de distribución y el agotamiento

6. Al respecto es importante señalar que si bien en la legislación estadounidense se reconoce el copyright el cual se diferencia del derecho de autor del sistema continental, pese a que existen diferencias ambos debido a sus orígenes, estos se han ido acercando cada vez más debido a la regulación internacional de estas materias, lo que hace pertinente que se haga alusión a la legislación estadounidense en esta materia. 
de este derecho en las secciones $106(3)^{7}$ y I09. ${ }^{8}$ Respecto de esta última sección, es destacable la forma en que se formula el agotamiento, ya que es formulado desde el punto de vista del dueño de la copia — al garantizarle la libre disposición respecto de su copia, sin necesidad de pedir autorización al autor o titular del derecho de autor- en vez de hacerlo desde la vista del agotamiento del derecho mismo.

Tal vez esta diversa formulación se deba a la historia misma que ha tenido la doctrina de la primera venta en Estados Unidos. Efectivamente, si bien esta institución adquirió rango legal con la dictación de la Copyright Law de $1909,{ }^{9}$ la verdad es que no fue más que la consagración de una doctrina que había surgido a nivel jurisprudencial el año anterior (Even, 2008: 4-5). Se trata del caso de Bobbs-Merrill Company $v$. Strauss.

Bobbs-Merrill había publicado el año 1904 la novela The Castaway, de Hallie Herminie Rives (Perzanowski y Schulz, 2010: 908). Con el fin de mantener el precio inicial de venta, el autor imprimió los libros con una nota que establecía que el libro no podía venderse a menos de un dólar y que cualquier venta hecha por un precio menor se consideraría una infracción a los derechos de autor (Perzanowski y Schulz, 20ıо: 908). El demandado vendió copias de este libro por sólo 89 centavos, producto de lo cual fue demandado por Bobbs-Merrill. La Corte en de-

7. $\int$ I06. Derechos exclusivos de derecho de autor. Sin perjuicio de las secciones I07 a I22, el titular de un derecho de autor bajo este título tiene el derecho exclusivo para hacer y autorizar cualquiera de las siguientes: (3) distribuir copias o fonogramas de las obras protegidas al público por venta u otra transferencia de propiedad, o en alquiler, arrendamiento o préstamo.

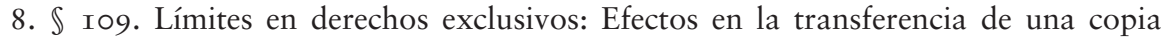
o fonograma: (a) Sin perjuicio de lo dispuesto en la sección Io6 (3), el dueño de un fonograma o copia particular hecha de manera leal bajo este título, o cualquier persona autorizada por este dueño, está facultado, sin la autorización del titular del derecho de autor, para vender o de otra manera disponer de la posesión de esa copia o fonograma.

9. $\$$ 4I. Que el derecho de autor es distinto de la propiedad sobre el objeto material que contiene la obra, y la venta o traspaso, por obsequio o cualquier otro, del objeto material no podrán por sí solo transferir el derecho de autor, ni de la cesión del derecho de autor se constituye una transferencia de la titularidad del objeto material; pero nada en esta Ley se considerará para prohibir, prevenir o restringir la transferencia de cualquier copia de una obra protegida por derecho de autor cuya posesión haya sido obtenida legalmente. 
finitiva rechazó la demanda, argumentando que una vez que el titular de derecho había vendido en una primera venta las copias en cantidades y a un precio satisfactorio, se entendía que había agotado ese derecho respecto de esas copias particulares. ${ }^{\text {IO }}$

En definitiva, más allá de lo llamativo que pueda resultar la manera en que está consagrada la doctrina de la primera venta en la ley estadounidense, lo esencial de esta formulación es que no distingue entre copias materiales y digitales. ${ }^{\mathrm{II}}$ Así se establece en el estudio del Berkman Center for Internet and Society sobre el negocio de iTunes:

La comprensión base de la forma en que está codificada la doctrina de la primera venta en la ley de derecho de autor es que no distingue entre copias 'análogas' y 'digitales'. Visto desde este ángulo, existen argumentos fuertes para decir que la doctrina de la primera venta, en principio y en términos generales, aplica a ambos formatos, siempre que los prerrequisitos esbozados antes sean conocidos y los límites de la doctrina sean respetados. (Gasser y otros, 2004: 55)

Por supuesto que la solución final no es tan simple como distinguir si la letra de la ley admite o no el entorno digital para la aplicación de la doctrina de la primera venta, pero de todas maneras es relevante tenerlo en cuenta.

Nos falta aún una norma más de la Copyright Act que revisar: la Sección II7, sobre la limitación a derechos de autor exclusivos y los programas de computador. Esta sección garantiza a los dueños de copias legales de programas de computador el derecho de reproducir, adaptar

Iо. «En nuestra opinión las normas de derecho de autor, mientras protegen al titular en su derecho de multiplicar y vender su producción, no crea el derecho a imponer, por notificación, tal como se describe en este caso, una limitación a la que el libro se venderá al por menor por los compradores futuros, con quien no hay relación contractual. Esta conclusión se alcanza en vista de las palabras de la norma, leída en vista de su propósito",Sentencia Corte Suprema de los Estados Unidos de fecha I de junio de I 908 en caso Bobbs Merryl Company vs. Strauss.

I I. Como vimos, por ejemplo, en los Tratados de la OMPI, donde el agotamiento se formulaba en torno a la definición del derecho de distribución, existe la limitación conceptual de que el derecho de distribución se refiere sólo a copias tangibles. Dicha limitación —insistimos, solo conceptual— no la encontramos en el derecho estadounidense. 
y redistribuir las copias de los programas de computador (Perzanowski y Schulz, 2010: 922). En específico, los actos permitidos por la Sección I I7 son los siguientes:

- Hacer una copia adicional o adaptación: Se refiere a copias de programa de computador hechas con el fin de utilizar el programa en conjunto con una máquina, en donde la copia es vista como un paso esencial para su utilización, y no puede ser usada con otro fin.

- Arrendamiento, venta u otra transferencia de la copia adicional o adaptación: Se refiere a que las copias de programa de computador hechas de acuerdo a la presente sección pueden ser arrendadas o vendidas junto con la copia original, pero sólo como parte de la venta o el arriendo u otra transferencia de todos los derechos del programa.

- Mantenimiento o reparación de la máquina: Este acto se refiere a las copias de programa de computador hechas con el fin de activar el programa en una máquina que contiene una copia autorizada de éste, sólo con propósitos de mantener o reparar la máquina, y bajo las condiciones de no usar la copia para otro fin, la cual debe ser destruida una vez cumplido su único propósito.

La Sección I 7 reconoce que los dueños de una copia de un programa de computador requieren más que sólo la libertad de alienación para poder hacer uso de la copia (Perzanowski y Schulz, 2010: 922). En otras palabras, la norma se desmarca de la estricta mirada del agotamiento del derecho de distribución, y va un poco más allá, buscando el uso óptimo de la obra, sin por ello dejar de respetar el derecho de autor.

Para terminar esta revisión por las normas del sistema norteamericano de agotamiento del derecho nos queda por revisar la Digital Millenium Copyright Act (DMCA). Como mencionamos hace algunos párrafos, esta ley fue dictada en el año I998 con el fin de implementar los Tratados de la OMPI sobre Derechos de Autor, y sobre Ejecución o Interpretación de Fonogramas y Reproducción. Es, por lo tanto, la respuesta estadounidense para la adaptación del derecho de autor a la llegada de internet y las nuevas tecnologías.

Respecto de las medidas adoptadas por Estados Unidos que se plas- 
man en esta ley, nos preocupa una en particular, porque pueden surgir dudas respecto de la viabilidad de la doctrina de la primera venta en un entorno digital: la Sección I20I (a), sobre elusión de sistemas de protección de derechos de autor (Perzanowski y Schulz, 20I0: 904). Esta norma prohíbe la elusión de medidas tecnológicas que restringen el acceso y la copia de obras protegidas por copyright, así como la creación o distribución de herramientas que faciliten esta elusión. Como podemos apreciar, resulta una norma altamente restrictiva para los usuarios de obras protegidas.

Entendemos que el objetivo principal de esta norma es evitar la violación, o más bien, garantizar el respeto a los derechos legítimamente adquiridos sobre una obra. Con estas medidas se busca recuperar un poco el control entregado por el copyright, que los titulares veían perdido con la llegada de internet (Lessig, 2005: I33). Sin embargo, no deja de ser preocupante cierta pérdida de equilibrio en la adopción de políticas sobre el copyright. Recordemos que uno de los objetivos principales de la doctrina de la primera venta es equilibrar los intereses del titular del derecho de autor y los del público, es decir, los de la sociedad. Y la adopción de normas como la Sección I 20 I no sólo impiden el desarrollo de herramientas de equilibrio ya consagradas, como es la doctrina de la primera venta, sino más aún, coarta los derechos legítimos de uso de los usuarios respecto de la copia de la obra de la cual son legítimos dueños. En definitiva, genera una situación irracional de desigualdad que va en desmedro de los intereses de la sociedad, principal beneficiada de las creaciones del intelecto humano, y, por lo tanto, nada aporta al crecimiento y desarrollo de aquella.

Hemos hecho hasta acá una breve revisión que nos ha servido para asimilar el escenario actual del tema que nos convoca. Sin ánimo de adelantar conclusiones, nos gustaría hacer notar ciertos tópicos determinantes para el análisis posterior. En primer lugar, el fondo de la regulación. Como vimos, ninguna de las normas revisadas profundiza mayormente en el agotamiento del derecho. Los cuerpos normativos que individualizan el derecho de distribución lo conceptualizan de manera similar para consagrar luego, en términos simples, su agotamiento posterior a la primera venta. No obstante, no hay mayor regulación en la materia. Por supuesto que las normas responden a los requerimientos de la vida en sociedad y, en este sentido, en la medida en que el mercado y las relacio- 
nes sociales a nivel mundial se han ido conectando y complejizando por la influencia de internet y el desarrollo de la tecnología, se hace necesaria una mejor regulación en la materia, que abarque estos nuevos escenarios virtuales que se han ido instalando.

Justamente por esto es que surgieron los tratados de la OMPI, que intentaron establecer el alcance de los derechos de autor en un entorno digital. Sin embargo creemos que en materia de agotamiento se podría haber avanzado más de lo que se hizo.

La libertad que otorgan los tratados de la OMPI a los Estados para regular la materia del agotamiento no hace más que dificultar su implementación en un entorno digital — si entendemos internet como un gran mercado global, donde las fronteras geográficas desaparecen-, pues mientras no exista un criterio común que guíe las diversas legislaciones nacionales, ninguna de éstas podrá dar solución a esta disyuntiva. Es el derecho internacional quien debe adoptar una postura clara respecto al agotamiento en un entorno digital. Visto de esa manera, nos parece que los últimos tratados en la materia son insuficientes.

\section{¿QUÉ OCURRE CON INTERNET?}

PROBLEMAS QUE SE PRESENTAN EN UN ENTORNO DIGITAL

Las principales trabas que identificamos para la implementación del agotamiento en internet son las siguientes.

I. Inmaterialidad: El problema de la inmaterialidad dice relación con la tradicional concepción del derecho de distribución y con la dificultad de implementar este derecho en un medio virtual, inmaterial, como internet.

Internet se caracteriza por ser un medio completamente nuevo y diferente a lo que estábamos acostumbrados en el mundo material.

[Internet] está instalada sin tener en cuenta las fronteras de los Estados y dominando un territorio que es siempre infinitamente superior al sometido a los poderes de aquellos. La gran red [...] permite la comunicación internacional de un modo nuevo, en el que las referencias territoriales se pierden y también se difuminan los poderes que gobiernan cada trozo de espacio físico sobre el que están constituidos los Estados. Es un territorio abierto: el ciberespacio, un mundo sin fronteras (Muñoz, 2000: 7). 
Sin embargo, como vimos antes, el Tratado de la OMPI sobre Derecho de Autor consagra la existencia del derecho de distribución junto con una declaración concertada en la que se indica que las copias a las que se refiere este derecho "se refieren exclusivamente a las copias fijadas que se pueden poner en circulación como objetos tangibles». Esta concepción ha sido recogida por gran cantidad de legislaciones nacionales (por ejemplo, la chilena), mientras que en otros casos, sin haber un reconocimiento expreso del carácter tangible de las copias en que recae el derecho de distribución, se subentiende por parte de la doctrina y/o jurisprudencia (por ejemplo, el caso de Estados Unidos).

Por lo tanto, vistas las condiciones actuales del derecho de distribución y conociendo lo diferente que es desarrollar un mercado en un entorno digital, la pregunta de fondo es ¿qué tan relevante es este requisito de tangibilidad para la concepción del derecho de distribución? ¿Es insalvable y, por lo tanto, inaplicable en un medio digital? ¿O por el contrario es posible y/o necesario modificarlo con miras a concebir una teoría del agotamiento digital?

A la discusión entran en juego varios argumentos, a favor de una y otra postura. A favor del agotamiento digital podemos decir que la concepción de derecho de distribución introducida en el Tratado de la OMPI, en particular su declaración concertada, no es en ningún caso limitante o excluyente de determinado tipo de mercado (el material o análogo), sino que simplemente tiene por objeto establecer un estándar mínimo de protección al derecho de distribución, y, en virtud de ello, en nada limita que un país decida ampliar el nivel de protección ofrecido por esta norma $-\mathrm{y}$ ampliar su aplicación, por ejemplo, a la distribución a través de la reproducción por medio de la transmisión digital-, lo cual podría hacerse en virtud de lo establecido en la solución marco (Ficsor, 2003: 215). Además, siempre hay que tener en consideración el fin último perseguido por el sistema de protección del derecho de autor, ${ }^{\mathrm{I} 2} \mathrm{y}$ en tal sentido, el rol fundamental que juega en el cumplimiento de dicha tarea la teoría del agotamiento del derecho,

I2. En Estados Unidos, por ejemplo, este fin último se encuentra reconocido en la sección 8 del artículo I de la Constitución, y consiste en buscar un equilibrio entre el derecho del artista a tener control sobre su obra, y la necesidad pública de acceder a estas obras (Grunewaldt, 20II: 3-4). 
asegurando un equilibrio entre los intereses del autor y los intereses del público general. ${ }^{\text {³ }}$

En contra del agotamiento digital, en virtud del carácter inmaterial del medio, podemos distinguir los siguientes argumentos. En primer lugar, la persistente calidad de la información digitalizada, así como sus bajos costos de distribución (Gasser y otros, 2004: 54). En un medio material, las copias ingresan al mercado y después pueden ser revendidas, arrendadas, etcétera; además, las copias se gastan y van perdiendo su calidad con el tiempo, lo cual permite distinguir claramente entre una copia nueva y una copia usada. Sin embargo, esta distinción entre una copia nueva y una copia usada se pierde completamente gracias a la digitalización. En virtud de lo anterior, los autores argumentan que los efectos propios de la teoría del agotamiento fueron concebidos para un medio material, en el cual puede distinguirse claramente entre una y otra copia, y, por lo tanto, no corresponde repetir estos efectos jurídicos del agotamiento en un medio digital, donde la condiciones son completamente distintas, pues se estaría en la práctica produciendo un efecto completamente diferente al que ocurre en un mercado con bienes materiales (Gasser y otros, 2004: 54).

Sumado a lo anterior, está el hecho de que en un medio digital la difusión de una obra se puede hacer al instante, en cualquier parte del mundo y por un costo insignificante. Esto reafirma el argumento central de que no corresponde intentar adaptar la teoría del agotamiento en un medio digital, en cuanto el contexto en el cual intenta aplicarse, así como las consecuencias que produciría son completamente distintas a las que se producen en un mercado material.

Por lo demás, se puede argumentar en contra de un agotamiento digital en función de las normas internacionales vigentes de derecho de autor, en particular las reglas contenidas en el Tratado de la OMPI sobre el Derecho de Autor. La tangibilidad, en dicho cuerpo normativo, establece un estándar mínimo de protección y no se ha adoptado ningún régimen de protección mayor. En virtud de lo anterior, es que debería

I3. «La doctrina de la primera venta ha sido un importante baluarte en la prestación de acceso público al facilitar la existencia de tiendas de libros y discos usados, tiendas de arriendo de videos, y, tal vez más significativamente, bibliotecas públicas» (Reese, 2003: 577). 
seguirse el sistema de agotamiento actualmente vigente, que aplica sólo a los medios tangibles.

2. Infracción a otros derechos de autor: derecho de reproducción y la memoria RAM: La esencia del problema del derecho de reproducción y las copias RAM (de su nombre en inglés, Random Access Memory) ${ }^{\mathrm{I} 4}$ radica en el tratamiento legal que se le ha dado a las copias RAM, lo cual repercute directamente en la doctrina de la primera venta (Perzanowski y Schulz, 20I0: 904). En la era análoga la compra y uso de copias protegidas por derecho de autor no implicaba la infracción de otros derechos exclusivos del titular de derecho; sin embargo, en el nuevo entorno digital no se puede afirmar lo mismo sin al menos dudar, ya que la transmisión de datos por vía digital sigue distintos patrones (Perzanowski y Schulz, 2010: 904) y estos nuevos patrones, de acuerdo a ciertos sectores, implicarían la infracción a ciertos derechos de autor.

Pero para entender bien en qué consiste esta dificultad, debemos saber primero en qué consisten estos nuevos patrones. La transmisión digital de datos funciona en torno a la memoria RAM del computador. Como se explica en la siguiente cita:

Todos los datos e instrucciones procesados por un computadorcomo ejecutar un software, navegar en la web, o mostrar información sin siquiera descargarla en el disco duro- son necesariamente reproducidos por cierto período de tiempo en la memoria del computador conocida como RAM. Por otra parte, al transmitir datos por internet, varias copias temporales se hacen no sólo en la memoria RAM del computador que lo envía, sino también en el computador remitente, en varios routers en internet, en la dirección del proveedor del servicio y en el computador receptor (Gasser y otros, 2004: 56; la traducción es nuestra).

Por lo tanto, vemos que, para que opere la transmisión digital de

I 4. Nuestra ley de derecho de autor, por ejemplo, define la reproducción en su artículo 5 letra u) señalando que es «la fijación permanente o temporal de la obra en un medio que permita su comunicación o la obtención de copias de toda o parte de ella, por cualquier medio o procedimiento». De esta definición podemos ver que incluye expresamente la «fijación temporal», dentro de la cual caben las reproducciones hechas en la memoria RAM del computador. Abordaremos a fondo este tema más adelante. 
datos se realizan por cada acto una reproducción del archivo en la memoria RAM del computador. De todas maneras, lo fundamental de estas reproducciones es su carácter temporal, en virtud del cual no permanecen en la memoria del computador por más tiempo del que toma llevar a cabo la actividad específica y desaparecen al apagar el dispositivo, o cuando la información simplemente es sobreescrita.

La dificultad misma de este tema, que afecta a la doctrina de la primera venta, se presenta al momento de entregarles un carácter jurídico a estas copias temporales. Y es que los tribunales han desarrollado la denominada Doctrine of RAM copies, doctrina en virtud de la cual, cada una las reproducciones temporales tienen el carácter de reproducciones de acuerdo a las leyes ${ }^{15}$ que protegen el derecho de autor. ${ }^{16}$

Esta doctrina ha sido instada mayoritariamente en algunas cortes por los titulares de derecho, intentando con ella extender los derechos de autor a las redes tecnológicas (Reese, 2001: 84). Y en la medida en que el uso de la información en formato digital se ha incrementado de manera explosiva en los últimos años, hace que las consecuencias de una interpretación de este tipo sean extremadamente significativas (Reese, 200I: I3 8). ${ }^{\mathrm{I}}$

Para la doctrina de la primera venta las consecuencias son claras y decisivas: en la medida en que las copias RAM sean consideradas reproducciones, un usuario no podrá llevar a cabo un acto de disposición de su copia en un entorno digital sin que esta acción derive en uno o varios actos de reproducción. La sola transmisión digital del archivo, desde el computador del revendedor, al computador del comprador, crearía varias copias temporales de la obra. Y como la teoría de la primera

I5. Hablamos de «leyes» en genérico, aunque la verdad es que el desarrollo jurisprudencial de esta materia se ha desarrollado principalmente en Estados Unidos, por lo que la definición de infracción de dicha doctrina se hace en base a la concepción de reproducción contenida en la Copyright Act.

I6. En términos generales, la doctrina de las copias RAM es aquella que establece que la accesión a obras protegidas por derecho de autor hecha a través de un computador infringe el derecho de reproducción porque requiere almacenamiento temporal en la memoria RAM de dicho computador (cf. Reese, 200I: 84).

I7. En este artículo sólo nos referiremos a las consecuencias que esta doctrina tendría respecto del agotamiento del derecho de distribución. Para leer más al respecto, véase Reese (200I) y Perzanowski (2009). 
venta garantiza la excepción del derecho de distribución, pero no el de reproducción, los actos de transferencia electrónica de obras digitalizadas a través de la red de computador no estarían permitidos en virtud del agotamiento. Por lo tanto, dichos actos no podrían llevarse a cabo sin infringir la ley de derecho de autor (Gasser y otros, 2004: 56).

\section{Facilidad para infringir los derechos de autor en un entorno digital:} Otro impedimento para la aplicación plena del agotamiento del derecho en redes digitales se refiere al medio virtual como un medio propicio para infringir el derecho de reproducción. Básicamente por dos cosas: porque al revender un archivo digital, en verdad no se está vendiendo el archivo, sino más bien una copia del archivo del revendedor —esto es, una reproducción - y porque al subirlo a la red, el archivo no se elimina del disco duro donde se encuentra almacenado, sino que simplemente se reproduce una copia idéntica. ${ }^{18}$ Entonces, desde el momento en que para desarrollar cualquier tipo de transacción - ya sea por medio de redes digitales o por medio de un soporte físico, pasando un archivo descargado de música a un soporte de este tipo, como un cedé, y entregando un cedé con la copia del archivo al comprador (Gasser y otros, 2004: 56) - el usuario revendedor tiene que reproducir la obra, se produce una infracción al derecho de reproducción (Gasser y otros, 2004: 56).

Además, para evitar una violación adicional a este derecho, se requiere un acto positivo por parte del usuario revendedor: se requiere que, una vez realizada la transacción, elimine el archivo de su disco duro; y a menos que se desarrollara una tecnología del tipo «reenviar y borrar», este acto dependería únicamente de la voluntad de la persona de guardar una copia del archivo revendido. Pero aunque el usuario revendedor borrara de su computador cualquier registro del archivo revendido, de todas maneras la infracción al derecho de reproducción ya se habría producido.

Como puede apreciarse, las nuevas tecnologías entregan todas las facilidades a los usuarios para reproducir cuantas veces quieran las copias de las obras protegidas, sin siquiera ver afectada la calidad de ellas. Por lo tanto, los defensores acérrimos del derecho de autor argumentan que una posible expansión del agotamiento digital a las redes digitales y los

I 8. Véase la opinión de Sam Díaz en Davis (2009: 368 ). 
eventuales beneficios que se pudieran obtener de ello, no compensarían la probabilidad de aumentar los daños a la protección dada al derecho de autor (United State Copyright Office, 200I: xix).

4. Obstáculo tecnológico: Medidas tecnológicas de protección. En el capítulo anterior describimos la sección I20I de la Digital Millennium Copyright Act (DMCA) con el fin de poder comprender mejor uno de los obstáculos relacionados con la DMCA a la hora de implementar la doctrina de la primera venta en un entorno digital. Pues bien, ahora nos encargaremos de explicar en qué consiste esta dificultad.

Sabemos que la DMCA prohíbe la elusión de medidas tecnológicas que restrinjan el acceso y la copia de obras protegidas, así como la creación o distribución de herramientas que faciliten esta elusión. Esta medida ha generado controversia y preocupación en diversos sectores por lo restrictiva que podrían resultar estas modificaciones al estatuto del derecho de autor norteamericano ${ }^{19} \mathrm{y}$, como era de esperar, estas limitaciones contenidas en la sección I20 I han alcanzado también a la doctrina de la primera venta.

Para comprender cómo la DMCA limita los beneficios de la doctrina de la primera venta, debemos mencionar la piedra angular que conforma este obstáculo: las denominadas tethered copies o copias atadas. Las copias atadas son copias que están encriptadas con una clave que utiliza una característica única de un aparato específico, como, por ejemplo, el número de identificación de una CPU, para asegurarse que no puedan ser usados en ningún otro dispositivo. Como explica el DMCA Report, aun cuando esta copia fuera descargada directamente a un medio removible, como un disco o un cedé, el contenido no podría ser accedido en ningún dispositivo distinto de aquel en el cual fue hecho (United State Copyright Office, 200I: 75). Dicho en otras palabras, el usuario pierde

I9. Desde la dictación de las DMCA, la Copyright Office ha realizado diversos estudios donde se evalúa el impacto de la era digital en las obras protegidas por copyright. Para el estudio de los efectos de las modificaciones de la DMCA (en particular su título I) en el desarrollo del comercio electrónico y las tecnologías asociadas a la operación de las secciones iog (que consagra la doctrina de la primera venta) y I I7 de la Copyright Act, es que se realizó el DMCA Section ro4 Report, del año 200I. En particular evalúa la posibilidad de implementar una doctrina de la primera venta digital (United State Copyright Office, 200I: I-2). 
toda libertad de uso que podría tener sobre su copia, pues ésta se encuentra atada a un determinado dispositivo para su utilización, ${ }^{20}$ restringiendo los diferentes usos por parte del usuario. Por ejemplo, si éste quisiera revender un archivo de música legalmente adquirido, la única manera de hacerlo sería revendiéndolo junto con el dispositivo que lo contiene, ya sea un ipod, un reproductor de $\mathrm{mp}_{3}$, o el disco duro de su computador. ${ }^{2 \mathrm{I}}$

Así, las copias atadas, y en general la sección I 20I, anulan los beneficios adquiridos en virtud de la doctrina de la primera venta. Analicemos en detalle cómo se ven afectados estos beneficios.

En primer lugar, las copias atadas amenazan con reducir los beneficios de disponibilidad y asequibilidad propios del agotamiento (Perzanowski y Schulz, 20ı0: 906). Las copias atadas frustrarían la opción de los usuarios de acceder y usar copias de obras protegidas que hubieran sido adquiridas por medio de mercados secundarios. ${ }^{22}$ Más aún, producto de las copias atadas difícilmente podría tener lugar un mercado secundario sin implicar infracción a la ley y la consiguiente responsabilidad de los usuarios por eludir las medidas tecnológicas de protección que evitan el pleno uso de la copia adquirida de segunda mano.

La falta de mercados secundarios, a su vez, acarrea una serie de consecuencias. La más importante es que entrega todas las facilidades a los titulares de derecho de autor para discriminar precios (Perzanowski y Schulz, 20I0: 907). Facilita la discriminación de precios, pues el titular

20. «En el caso de las obras atadas, aún si la obra está en formato extraíble, el contenido no puede ser accedido en ningún dispositivo que no sea aquel en que fue originalmente hecho. Este proceso evita efectivamente la disposición de la obra» (United State Copyright Office, 200I: xvi-xvii).

2I. «Los consumidores, sin embargo, tal vez encuentren estas copias más difícil de transferir bajo la doctrina de la primera venta comparadas con las copias distribuidas de manera tradicional. Para empezar, muchas obras descargadas estarán almacenadas en el disco duro del usuario [...] pero transmitir el objeto material —el disco duroimplicará remover el disco del computador (o vender el computador con el disco duro), y además transferir todos los otros datos en el disco duro (o removerlos del mismo. Bajo las condiciones de la doctrina de la primera venta, transferir un disco de música que ha sido descargado en un disco duro será mucho menos conveniente que vender ese disco usado» (Reese, 2003: 6I 2). Véase también Gasser y otros (2004: 57-58).

22. "Mientras en el corto plazo la DMCA [...] pareciera irrelevante en la prevención de la piratería, su efecto en mercados secundarios es inmediato y significativo» (Gasser y otros, 2004: 48). Véase también Perzanowski y Schulz (2010: 904-905). 
del derecho ya no tiene mercados secundarios con los cuales competir, al estar los usuarios imposibilitados de revender sus copias, en virtud de las medidas tecnológicas ineludibles (Reese, 2003: 626). Además, a través de la diseminación digital, el titular del copyright tiene mayores facilidades para identificar a los grupos de consumidores, donde unos están dispuestos a pagar más, y otros a pagar menos (Reese, 2003: 626). Si esto es beneficioso o no para los usuarios, va a depender del usuario particular del que se trate.

En general, los usuarios que resultan perjudicados son aquellos consumidores especializados o más instruidos, dispuestos a pagar más (Perzanowski y Schulz, 2010: 907), mientras que aquellos que no buscan copias de una determinada obra con características especiales, podrían acceder a ella a precios más bajos. Visto así, pareciera no constituir un efecto negativo para los usuarios a priori, simplemente un efecto distinto, que pese a perjudicar a unos pocos, pareciera favorecer a la mayoría. Sin embargo, el tema relevante es que no queda claro que esta discriminación de precios resulte más beneficiosa para las consumidores, que lo que resulta para los mercados secundarios (Perzanowski y Schulz, 20 Io: 907). Sí es más fácil de predecir que la discriminación de precios favorece a los titulares de derecho, y les permitiría obtener un mayor beneficio económico, y, por sobre todo, les permitiría un mayor poder para determinar el excedente a obtener.

Por otro lado, tenemos los efectos sobre la disponibilidad de las obras. En general, ésta se ve afectada por la existencia de copias atadas, por cuanto el acceso a las obras lo tendrían sólo en aquellos lugares donde el titular del derecho decida hacer ventas (Perzanowski y Schulz, 20I0: 907). Además, al no existir la opción de los mercados secundarios, los usuarios sólo podrían acceder a las obras por la vía del titular del derecho de autor, y, por lo tanto, éste se constituiría en la única vía de acceso a las obras protegidas. La opción del público de acceder a una determinada obra dependería de la decisión de una persona: el titular del derecho de autor. Por lo tanto, se ve puesto en peligro el efecto de disponibilidad de las obras, y, especialmente, el efecto de preservación de las obras.

Aparte de los efectos de disponibilidad y asequibilidad, también podrían verse afectados los beneficios sobre la privacidad de los usuarios respecto del uso de su copia. Como vimos algunos párrafos atrás, la 
doctrina de la primera venta permitía un uso anónimo de las obras, pudiendo disponer de ellas sin necesidad de que el titular del derecho de autor interviniera. Con las copias atadas, este beneficio se pierde, pues muchas de estas medidas de protección requieren, para poder acceder a la obra, conectar con el servicio que otorga acceso a la obra, y, en general, entregar algún tipo de información personal que permita identificar al usuario (Perzanowski y Schulz, 2010: 909).

Por último, las copias atadas aumentan los costos de información y transacción. Al ser copias sujetas a medidas tecnológicas, al momento de la compra hay gran cantidad de información a considerar adicional a la que se requeriría en la compra de una obra en un medio material, como son las condiciones legales o de uso asociadas a la copia (Perzanowski y Schulz, 2010: 909).

4. Obstáculo jurídico: Contratos de licencia. Otro obstáculo que encontramos para la aplicación del agotamiento del derecho en un entorno digital son los contratos de licencia. Este obstáculo, a diferencia de los otros descritos hasta ahora, tiene un origen contractual, fomentado por las principales industrias relacionadas al derecho de autor. ${ }^{23}$

Sabemos que para obtener los beneficios propios de la doctrina debe darse un requisito esencial: que el usuario sea dueño de la copia. Sólo aquellos que tengan esta calificación pueden ejercer los derechos que les otorga el agotamiento. En vista de lo anterior, los titulares de derechos de autor han buscado cambiar la figura jurídica tradicional de los contratos que recaen sobre copias digitales de obras protegidas por derechos de autor. Así, se ha dejado de contratar la acostumbrada venta, para cambiarla por contratos de licencia. A saber, la licencia «es un contrato en virtud del cual el titular de un derecho de propiedad intelectual permite o autoriza que otra persona utilice la creación mediante el pago de determinada cantidad de dinero a título de regalía o retribución económica» (Rengifo, I997: 163).

Es un contrato que permite el uso de la copia de la obra, sin transferir el dominio de la misma. Por lo tanto, el efecto jurídico de este cambio contractual es que los usuarios ya no se convierten en dueños de la copia,

23. Esta práctica comenzó a ser implementada por las empresas distribuidoras de software Véase Carver (20II: I 896-I897). 
pues no es la propiedad del bien lo que se estaría negociando, sino un permiso de uso del bien en virtud del cual el usuario puede justamente usar la copia, pero no prestarla, revenderla o ,en general, disponer de ella. En otras palabras, el usuario, en virtud del contrato de licencia, no se convierte en dueño de la copia, y por lo tanto no puede tener aplicación la teoría del agotamiento del derecho (Perzanowski y Schulz, 20ıо: 905).

Es importante hacer notar que éste es uno de los principales impedimentos para la aplicación de la teoría del agotamiento del derecho en un medio digital y que es un problema de origen contractual: son los propios titulares de derecho quienes han implementado esta práctica. No hay ninguna ley o norma que imponga esta limitación. El hecho de que estas medidas restrictivas provengan de la autonomía de la voluntad resulta especialmente grave por las consecuencias que conlleva el uso de contratos de licencia, que no son menores. Por ejemplo, en el caso de las bibliotecas:

Las condiciones de la concesión de licencias afecta sistemáticamente a los usos que eran tradicionalmente legítimos de conformidad con la doctrina de la primera venta. Las prácticas habituales de las bibliotecas autorizadas con arreglo a la ley sobre el derecho de autor, como los préstamos entre bibliotecas, los préstamos a las aulas o la utilización en el hogar de los clientes, el archivado, la conservación [...] han sido restringidas, en algunos casos fuertemente restringidas y en otros casos suprimidas, por acuerdos de concesión de licencias (ARL, 2002: 25).

Más aún, en el caso específico de la conservación histórica de las obras —es decir, la preservación de las obras, uno de los principales beneficios de la teoría del agotamiento-, las bibliotecas se han visto impedidas de llevar a cabo esta importante labor, producto de los contratos de licencias. Por estos contratos, las bibliotecas pierden el control de archivado y conservación, pues muchas licencias prohíben estos usos por parte de los usuarios (ARL, 2002: 28). Y si las bibliotecas, que son el principal actor encargado de archivar y conservar las obras de manera profesional, se ven impedidas de llevar a cabo esta labor, se produce un peligro importante de pérdida de obras para los autores y la sociedad (ARL, 2002: 28).

De todas maneras, el tema de los efectos jurídicos de los contratos 
de licencia —a saber, si son un contrato de venta «disfrazado», o si efectivamente sólo autorizan determinados usos de la obra- ha sido muy discutido en la jurisprudencia norteamericana, en donde se han formado opiniones claramente divididas y opuestas entre sí (Perzanowski y Schulz, 20I0: 904). Una de ellas, quizás la postura más extrema, se caracteriza porque el tribunal se centra casi exclusivamente en el significado de las palabras usadas en el contrato, sin ir más allá del contenido de éste (Carver, 20II: I 898). Este tipo de posturas facilitan enormemente el objetivo del titular del derecho de evitar transferir la propiedad de las copias a los usuarios (Carver, 20II: I898). En algunos casos, se ha llegado a los extremos de aceptar, como argumento suficiente, que el titular afirme en el contrato que licencia el bien, en vez de venderlo. Estas posturas extremas han sido denominadas por la doctrina como The magic words approach, por bastarle a estas cortes el uso de palabras mágicas como licencia para resolver la disputa (Carver, 20II: I 898). Uno de los casos que contiene estas posturas es MAI Systems Corp. $v$. Peak Computer, en el cual se concluye que los usuarios del software de MAI no son dueños del software que utilizan, en virtud del contrato de licencia que recae sobre el mismo. ${ }^{24}$

Una segunda postura, más avanzada, ha sostenido que si bien el título del contrato juega un rol relevante en la interpretación hecha por la corte, ésta va un poco más allá y examina más ampliamente el contenido del contrato, con el fin de determinar quién es el dueño de las copias protegidas (Carver, 20II: I898). Lo que se acostumbra hacer en este tipo de análisis es que el tribunal evalúa los términos del acuerdo para determinar qué restricciones y qué usos están garantizados en virtud del permiso (Carver, 20II: I906).

Otra posición es la que se caracteriza por resoluciones que, para determinar cuál es la realidad económica de la transacción, se atreven a ir más allá de los términos del contrato: «Los factores considerados pueden incluir términos del acuerdo no relacionados con el derecho de autor, así como hechos de la transacción no discutidos en ningún momento del acuerdo" (Carver, 20II: I9I 5). Esta jurisprudencia aporta uno de los elementos más valiosos para la teoría del agotamiento, al contener una mirada global, más completa, del conflicto. Al respecto, podemos

24. Ninth Circuit. I993. MAI Systems Corp. v. Peak Computer Inc. 
observar su razonamiento en algunos casos importantes como United Sates $v$. Wise ${ }^{25}$ y Microsoft Corp. v. DAK Industries. ${ }^{26}$

Aún nos queda mencionar una cuarta postura, la cual también rescata la realidad económica de la transacción, pero se diferencia de la anterior postura en cuanto ofrece una respuesta teórica más satisfactoria a la discusión jurídica sobre el derecho de posesión perpetua que se tiene sobre la copia (Carver, 20II: I 899). De acuerdo a lo que nos explica Brian Carver, existen dos fallos que han adoptado esta postura, que él denomina Perpetual Posession Approach y que son: UMG Recordings, Inc. v. Augusto ${ }^{27}$ y Vernor v. Autodesk, Inc. (Carver 20I I: I92I). ${ }^{28}$

En UMG Recording $v$. Augusto, la compañía UMG Recording demanda a Troy Augusto por vender en eBay cedés promocionales de UMG que contenían la indicación «Este CD es propiedad de la compañía y su licencia sólo permite su uso promocional»(Carver, 20I I: I92 I). La corte al momento de decidir adoptó el criterio seguido en el caso Wise, en el sentido que si el derecho a posesión adquirido es permanente, y el pago realizado no es correlativo al período de tiempo en que se goza de dicha posesión, entonces hay fuertes indicios que se ha transferido el dominio de la copia (Carver, 20II: I922-I923).

Además de los fallos revisados por Carver, existe un fallo más reciente que también sigue esta línea argumentativa. El caso de UsedSoft $v$. Oracle, ${ }^{29}$ del Tribunal de Justicia de la Comunidad Europea. Este tribu-

25. Ninth Circuit. I997. United States v. Wise. En este caso, se identifican dos elementos que resultan decisivos: la posesión de la copia y el pago. Esta postura fue seguida después para otros casos, como el de UMG Records (Carver, 20I I: I922).

26. Ninth Circuit. I995. United States v. DAK Industries.

27. Ninth Circuit 20I I. UMG Recordings Inc. v. Augusto.

28. Western District of Washington. 2008. Vernor v. Autodesk, Inc.

29. Los hechos del caso son los siguientes: Oracle es una empresa que desarrolla y distribuye software de bases de datos mediante descargas de internet. Por otro lado, UsedSofft es una empresa que comercializa licencias de segunda mano. Oracle demandó a Usedsoft por esta práctica, ganando en primera instancia, con el argumento de que los contratos de licencia de Oracle entregan un derecho de uso que no es transferible. La apelación fue desestimada, y en la interposición del recurso de casación, el tribunal decide remitirse al Tribunal de Justicia Europeo y plantearle que se pronuncie como cuestiones prejudiciales (Tribunal de Justicia de la Unión Europea, 20I2, Usedsoft $v$. Oracle). 
nal fue consultado, por medio de una medida prejudicial, por el tribunal que llevaba el caso en Alemania. El tribunal alemán le solicitó que se pronunciara, en definitiva, respecto de si la descarga de una copia autorizada por el titular da lugar al agotamiento del derecho, en vista que se encontraban frente a un contrato de licencia (Apartado 34, Tribunal de Justicia de la Unión Europea, 2012, Usedsoft v. Oracle).

Para adoptar su resolución, el tribunal europeo siguió el siguiente razonamiento: para determinar si hay o no agotamiento, es esencial determinar si la relación contractual presentada en el caso es equivalente a una "primera venta». Para ello, en primer lugar, consideró que la descarga de la copia y el contrato de licencia conformaban un todo indivisible. En segundo lugar, el tribunal tomó en consideración que el usuario, al pagar un precio, adquiere un derecho de uso ilimitado de la copia del software, por lo que se puede afirmar que hay una transferencia de la propiedad de la copia, y, en tal sentido, esta relación contractual es asimilable a una "primera venta». De esta forma, el Tribunal de Justicia de la Comunidad Europea concluyó que el agotamiento del derecho es aplicable a las copias descargadas por el usuario (Apartado 38, 44-48, Tribunal de Justicia de la Unión Europea, 2012, Usedsoft v. Oracle), independiente de si el software es puesto a disposición en un soporte material o a través de internet.

Creemos que este tipo de razonamiento debe ir ganando terreno dentro de la jurisprudencia y la doctrina del agotamiento del derecho. Rescatamos especialmente la intención del fallo de asimilar la relación contractual a la primera venta. Esta visión es la que debe primar para rescatar la institución y mantener el equilibrio existente antes de la llegada del mundo digital. De otra forma el riesgo de perder los beneficios que nos ofrece la doctrina de la primera venta seguirá presente.

5. Territorialidad: ¿Qué sistema de agotamiento ocupar? Este conflicto se refiere a la falta de unanimidad entre los Estados respecto a qué sistema de agotamiento aplicar. A priori, tal vez, parezca una discusión anticipada, en el sentido de que si no tenemos un reconocimiento indiscutido del agotamiento del derecho en medios digitales, sería apresurado preocuparnos de una discusión que parece ser de posterior relevancia en cuanto a su implementación. Sin embargo, creemos que ocurre todo lo contrario. Pareciera ser importante dedicarle unos párrafos, dado que 
esta discusión evidencia uno de los principales impedimentos de implementación del agotamiento: la voluntad política de los Estados.

Efectivamente, como vimos en el capítulo anterior respecto del Tratado de la OMPI sobre Derecho de Autor, durante las negociaciones de este instrumento se discutió respecto del tema del agotamiento, pero no se logró llegar a acuerdo. La principal razón fueron los diversos intereses económicos de los Estados partícipes de las negociaciones. No es indiferente la elección de uno u otro sistema: el sistema nacional es más restringido y protector de los intereses del Estado que los adopta —ad hoc para países donde el derecho de autor implica importantes ingresos económicos, por ejemplo Estados Unidos-, mientras que el sistema internacional fomenta la apertura de los mercados y la libre circulación de bienes. Por lo tanto, son las relevantes consecuencias económicas que conlleva adoptar uno u otro sistema que tornan casi imposible acordar la adopción mundial de un único sistema de agotamiento.

Más aún, si consideramos que internet se caracteriza por ser esencialmente aterritorial, ${ }^{30}$ lo lógico sería esperar que se adoptara un sistema de agotamiento internacional, que haga imposible implementar los efectos propios de algún otro sistema de agotamiento, sea nacional o regional. Además, si consideramos que toda la cuestión del agotamiento radica en el primer lugar de comercialización, y la digitalización ya dificulta localizar el lugar de esta primera venta (Gaubiac, 2002: I2), la manera más razonable de dar solución a este impedimento es mirar a internet como un solo gran mercado, cuya primera comercialización implique el agotamiento en todo el «territorio», que sería toda la red.

El problema de adoptar esta opción, tal como comentábamos, es que atenta contra los intereses económicos — legítimos, por cierto- de varios países, y ello se traduce, en consecuencia, en falta de voluntad política para dar el gran paso e implementar esta medida.

30. "Internet y, en general, la denominada sociedad de la información, se caracterizan esencialmente por el hecho de que los contenidos utilizados se dispersan por el conjunto de la red con una vocación mundial y sin una base territorialmente acotada. Por definición, los contenidos a explotar en internet son susceptibles de ser divulgados de manera automática e ilimitada en todo el mundo» (Erdozain, 2002: 75). 
Hasta aquí hemos presentado argumentos de diversa índole que se oponen a la aplicación del agotamiento del derecho en un medio digital. Nos corresponde, en consecuencia, analizar qué tan reales o ilusorios son estos impedimentos.

El primero de los argumentos decía relación con la falta de materialidad de internet y la relevancia de la tangibilidad en la concepción del derecho de distribución, abarcando dos tópicos para la discusión: por un lado, el alcance o las limitaciones que implicaría una regulación normativa y, por otro, las consecuencias reales que significaría el cambio a un contexto digital. Con respecto a la regulación, la normativa internacional garantiza claramente un estándar mínimo de protección en torno al derecho de distribución. Y, por lo tanto, no existe ningún impedimento para que una legislación nacional pueda optar por extender este derecho a las distribuciones hechas por medios de transmisión digital. La normativa internacional no prohíbe la ampliación del derecho de distribución a un medio digital, ni su consiguiente agotamiento. ${ }^{3 \mathrm{I}}$

Sin embargo, no basta con el reconocimiento de un derecho de distribución digital en uno o dos países: el hecho de que esta adaptación no esté consagrada en algún instrumento internacional dificulta, en parte, la efectividad que pudiera tener cualquier medida a favor del derecho de distribución digital por parte de un Estado o por grupo de ellos. De todas maneras, este reconocimiento parcial constituiría un avance y, seguramente, mientras más países garanticen este derecho, más probabilidades habrá de que se establezca una protección internacional para la distribución de las obras. Sabemos que los cambios normativos no se generan en plazos breves de tiempo, pero mientras haya discusión doctrinaria, jurisprudencial y legislativa se estará avanzando al respecto.

A lo anterior, podemos añadir que el carácter tangible de las copias protegidas no es de la esencia del derecho de distribución, puesto que el

3I. Más aún, como vimos al estudiar la solución marco del Tratado de la OMPI sobre derecho de autor, pudimos ver que si no se adoptó una postura determinada respecto a qué derecho se debía proteger en la transmisión digital de una obra, fue por diferencias políticas más que por algún argumento de fondo. La principal dificultad a nivel internacional es la de unificar la normativa respecto a esta materia. 
fin último de este derecho es asegurar un beneficio económico al autor por la explotación de su obra en el mercado, y si este mercado, gracias al desarrollo de la tecnología, se diversifica y adquiere nuevas características -como ocurre con el desarrollo del comercio electrónico en internet-, la tangibilidad pasa a ser un elemento de carácter secundario, pues lo relevante es que sigue existiendo un mercado, un lugar en el cual el autor puede introducir y explotar su obra y, lo más importante, obtener un beneficio económico por esta acción. Bajo esta lógica, entendemos que sí es posible concebir un derecho de distribución en un entorno digital.

Ahora bien, ¿es justo aplicar una teoría del agotamiento en medios digitales? ¿Bajo qué condiciones debiéramos permitir esto? A priori, pareciera ser que aquello sería justo en la medida en que se respeten o mantengan condiciones de aplicación similares a las que podemos encontrar en un entorno material. Sin embargo, nos parece que esta respuesta no basta. Es necesario ir más allá de este análisis y de los intereses de una u otra parte involucrada.

Refirámonos ahora al segundo tópico concerniente a los profundos cambios que internet ha generado en el contexto cultural y el derecho de autor, el cual se constituye como uno de los argumentos más fuertes para oponerse a una teoría del agotamiento del derecho digital.

Es verdad que en un entorno digital cambian las condiciones en que se desarrolla la comercialización de las obra. Es probable que genere una mayor competencia de precios para los titulares de derecho y que, en consecuencia, disminuyan los ingresos obtenidos en comparación a los que obtendrían en un mercado material, puesto que las copias obtenidas gracias a las nuevas tecnologías tienen la misma calidad que la obra original. Lo que en la práctica significa que es imposible distinguir un archivo nuevo — proveído por el titular del derecho- de un archivo revendido por un usuario, entregándole a este último un poder de competir de igual a igual con el titular del derecho de autor. Sin embargo, este cambio de condiciones no puede constituir un argumento suficiente, en la medida en que la opción contraria significaría vulnerar el interés público de acceso a las obras, de acceso a la cultura. No se puede pretender que el derecho de autor constituya una herramienta que sólo sirva para asegurar determinada retribución económica.

Al contrario, el derecho de autor, por medio de la teoría del agota- 
miento, es el que nos permite encontrar un equilibrio entre los intereses del autor y los del público. Sólo a través de su rol regulador, este interés general de la sociedad de acceder a las obras protegidas - que es uno de los objetivos principales de la regulación del derecho de autor (Rengifo, I997: 50)—, así como el interés de los autores de obtener una legítima retribución por su trabajo intelectual, se puede mantener intacto.

Por último, debemos considerar que, pese a la mayor competencia de precios que genera el agotamiento digital, internet entrega otro tipo beneficios a los autores y, en general, a los titulares de derecho, pues constituye una plataforma inmejorable para difundir y dar a conocer su trabajo, lo cual a su vez puede traducirse en una mayor retribución económica. En tal sentido, no todas las consecuencias generadas por internet son negativas para los autores. Al contrario, la red entrega una serie de beneficios a los autores y a sus audiencias. En definitiva, teniendo claro el objetivo del agotamiento del derecho y en qué medida está cumpliéndose con ese objetivo, la teoría resulta ser perfectamente aplicable al nuevo entorno digital.

En segundo lugar, encontramos el impedimento de la territorialidad. Este tema es, tal vez, el más simple y, a la vez, más complejo de resolver. Simple, en cuanto para lograr una solución basta con acordar, entre los distintos países, la aplicación de un único sistema de agotamiento en internet. Sin embargo, resulta de compleja solución, pues para tomar esta medida deben entrar a negociar los distintos intereses de los países involucrados.

Las consecuencias económicas de tomar esta decisión son relevantes y es en virtud de ello que lograr un acuerdo en la comunidad mundial es tan difícil. Nos parece que esta materia está marcada por aspectos políticos cuya revisión escapan del tema de este artículo. Por lo tanto, nos limitaremos a reflexionar sobre cuál creemos que debe ser el sistema de agotamiento óptimo a aplicar en un entorno digital y — por qué no- en un entorno material, también.

Como mencionamos antes, nos parece que la propuesta más lógica es adoptar un sistema de agotamiento internacional, porque resulta el único sistema adecuado frente a las características propias de internet. Los distintos sistemas de agotamiento se diferencian básicamente por el efecto que producen respecto a una determinada frontera, y tal diferenciación pierde sentido en un entorno donde no existe frontera alguna. 
Por eso decimos que es «lógico» aplicar un sistema internacional, porque otro sistema de agotamiento es difícil de llevar a la práctica. No lograría producir los efectos que se esperan.

Pero independiente que simplemente resulte lógico, nos parece que el sistema de agotamiento internacional debiera ser el sistema a aplicar en internet -y, por qué no, en un medio material- en cuanto resulta más favorable para los mercados internacionales, beneficiando especialmente a los países en desarrollo. El derecho de autor y la propiedad intelectual, en general, deben cumplir un rol clave en esta materia. Y, siguiendo ese objetivo, se debe optar por un sistema de agotamiento que garantice un mayor acceso a las obras, a través de una mayor competencia de precios y menor control sobre los bienes que se comercializan.

Vistos ya los temas de inmaterialidad y territorialidad, abordaremos ahora los argumentos que, a nuestro parecer, constituyen uno de los más fuertes impedimentos para la implementación de la teoría del agotamiento del derecho en internet. Éstos son: los contratos de licencia, las medidas tecnológicas de protección y la posible infracción al derecho de reproducción.

Respecto de los contratos de licencia, consideramos que constituye uno de los principales impedimentos, en cuanto se ha convertido en una práctica acostumbrada en el comercio electrónico. Al respecto, ya podemos apreciar algunos avances, gracias a cierta jurisprudencia estadounidense y europea. En efecto, fallos con líneas argumentativas como las que encontramos en Recordings, Inc. v. Augusto, Vernor v. Autodesk, Inc, y UsedSoft $v$. Oracle., consideramos que apuntan en la dirección correcta respecto de esta materia — en efecto, adherimos a la postura adoptada en estas sentencias- $y$, por lo tanto, consideramos que deben ser destacados.

Existe aún mucha división respecto de esta materia a nivel jurisprudencial. Así como encontramos sentencias que destacamos, tenemos también numerosa jurisprudencia que argumenta en un sentido contrario, en la medida en que reconoce el carácter jurídico de licencia a estos contratos. Nos parece que tales posiciones están erradas, en la medida en que la línea argumentativa desarrollada se queda en la superficie y no ahonda en el tema de fondo.

Lo importante es si puede permitirse o no a un titular de derecho de autor evadir ciertos efectos jurídicos propios establecidos en el sistema 
de derecho de autor, a través de un resquicio legal, como es el denominar «licencia» a un contrato que tiene claramente los efectos jurídicos de una compraventa. Si esperamos tener un sistema de protección de derecho de autor efectivo, nos parece que es fundamental que tal tipo de prácticas no sea permitida y, en tal sentido, la jurisprudencia puede jugar un rol relevante. En ningún caso estamos argumentando en contra del empleo de las licencias en sí. Al contrario, consideramos que es un modo legítimo de explotación de las obras que pueden utilizar los titulares de derecho y, más aún, que se ajusta perfectamente a determinados tipos de negocios desarrollados en internet. Así, por ejemplo, el uso de licencias se adecúa perfectamente al negocio de ciertas revistas, diarios o periódicos, en que el usuario paga un precio para consultar su contenido una vez, sin el interés de conservar la copia. Para este tipo de prácticas, la licencia es la figura jurídica a utilizar, en cuanto responde de manera plena a los requerimientos del usuario.

Son aquellos casos en que la posesión de la copia es traspasada de manera perpetua los que consideramos que no corresponde hablar de licencia, en cuanto no tiene más fin que evitar la correcta aplicación del derecho de autor.

Los titulares del derecho de autor argumentan que emplean contratos de licencias sobre las copias comercializadas en internet pues no es posible ser propietario respecto de este tipo de copias. ¿Y por qué no? El cambio tecnológico que supone internet en nada debiera alterar otros principios del derecho como es la propiedad. Tal como argumentamos algunos párrafos atrás, el hecho de que haya un cambio en el contexto en que se desarrolla esta discusión, no significa que debamos alterar las nociones fundamentales del asunto.

$\mathrm{Al}$ acceder a internet y adquirir legalmente un archivo de música, video, etcétera, el usuario está pagando un precio al igual que lo haría en un medio material. El hecho de que la copia no constituya un bien tangible y, por el contrario, sea adquirida como un bien intangible, no limita el hecho de que haya sido adquirida legítimamente. En tal sentido, en la medida en que el usuario pague el debido precio, y que por este acto adquiera el derecho a utilizar sin límites de tiempo la obra, debiéramos reconocer que el usuario ha adquirido la propiedad del bien.

Tal como se afirma en el apartado 49 de la sentencia de UsedSoft v. Oracle en relación a la aplicación del artículo 4.2 de la Directiva 
2009/24, y cuyo razonamiento extrapolamos a esta discusión de alcance más amplio, la concepción de «venta» debe interpretarse en un sentido amplio, pues de lo contrario se pondría en peligro el efecto útil de las normas de derecho de autor -en particular, de aquellas que versan sobre el derecho de distribución y su agotamiento- y bastaría con que los titulares de derecho "calificasen un contrato de 'licencia' en vez de 'venta' para soslayar la regla del agotamiento, privando a éste de toda eficacia» (apartado 49, Tribunal de Justicia de la Unión Europea, 20 2, Usedsoft v. Oracle).

Consideramos que será por medio del análisis caso a caso, y de la revisión de la realidad económica de cada cual, que se podrá seguir avanzando en esta materia, con miras a una implementación adecuada de los contratos de licencia, y del reconocimiento correspondiente de los contratos de venta.

De acuerdo a la descripción hecha en la sección anterior, podemos ver que se nos presenta un tema de muy difícil solución, en cuanto existe legislación como la DMCA que prohíbe su elusión.

En general, los titulares de derecho de autor argumentan que las medidas tecnológicas son un respaldo necesario en el contexto de las redes digitales, pues los derechos fundamentales que conforman el sistema de derecho de autor, como son el derecho de reproducción, de distribución o de comunicación pública, son letra muerta si no son implementados sobre la base de estas medidas tecnológicas (Martin-Prat, 2004: 86). Así, posicionan estas medidas como herramienta indispensable en la lucha contra la piratería y, en general, para el desarrollo de un mercado legal que beneficie tanto a los autores que buscan difundir sus obras, como a los consumidores que quieren tener acceso a ellas (Martin-Prat, 2004: 86).

Es verdad que las nuevas tecnologías pueden ofrecer un escenario incierto para los titulares de derecho de autor, que los hacen vulnerables en cuanto existen toda clase de facilidades para infringir diversos derechos y, en tal sentido, pierden esa seguridad que se tenía en un entorno material. Estamos de acuerdo con que los titulares de derecho tengan algún tipo de certeza en un contexto digital, y pueda seguir fomentándose la creación de obras intelectuales. Visto así, la utilización de medidas tecnológicas de protección no debiera tener a priori efectos negativos en la medida en que sean implementadas razonablemente, con miras a resguardar los derechos de sus titulares, pero, a la vez, que no se conviertan 
en un sistema que pierde todo equilibrio de regulación en desmedro de los usuarios. Lamentablemente, creemos que eso es lo que ocurre hoy con la Sección I 2or de la DMCA. Esta ley, que establece un régimen de antielusión estricto, cae en este juego de perder el equilibrio mínimo que esperaríamos en un sistema de derechos de autor.

Más aún, si consideramos que la Sección I20 I no sólo prohíbe la elusión de medidas tecnológicas, sino que además prohíbe el desarrollo de tecnología que permita llevar a cabo esta elusión, genera un escenario que entrega un control total a los titulares de derecho en desmedro de los usuarios.

Los principales afectados con esta medida son los propios consumidores, pues la elusión produce el efecto de anular derechos y, en general, beneficios legítimamente adquiridos por los usuarios de las copias de las obras. Con una prohibición de eludir medidas tecnológicas de protección se afectan los derechos legítimos que tiene una persona de disponer de su copia, y esta consecuencia, que podemos identificar a nivel individual, por supuesto que genera también consecuencias generales, a nivel del público. Como vimos, se anulan los efectos de disponibilidad y asequibilidad, que tienen un efecto directo en el acceso a las obras por parte de la audiencia, y ello tiene consecuencias aún mayores, debido a que significa la pérdida de acceso a la cultura, con consecuencias nefastas para la sociedad.

Si queremos obtener soluciones frente a este problema, lo primero que debemos tener claro es que los propósitos del sistema de derechos de autor no es maximizar el lucro de los titulares, sino proveer el incentivo suficiente para promover la creación de nuevas obras (Perzanowski y Schulz, 2010: 908). En vistas de ello, es necesario hacer presente que medidas como las de la DMCA no cumplen con este objetivo. Al contrario, evitan la creación de mercados secundarios y facilitan la discriminación de precios. Por lo tanto, creemos que estarían más bien facilitando el enriquecimiento de los titulares, ofreciendo un incentivo superior al necesario para fomentar la creación de nuevas obras. ${ }^{32}$

32. Por supuesto que la determinación de un incentivo «justo»o «necesario» es difícil de definir, pero hacemos esta aseveración en miras a la pérdida del equilibrio aparente que existe entre el acceso a las obras de público y la retribución económica del titular del derecho. Sostenemos que se ofrece un incentivo superior al necesario en la medida en 
Una posible salida que podría ofrecer la misma DMCA, se encuentra en la Sección I20I (c), que establece que nada de lo establecido en esta sección debiera afectar derechos, soluciones, limitaciones o defensas a la infracción del derecho de autor, incluido el uso justo. En tal sentido, si se argumenta que el agotamiento del derecho constituye una defensa a la infracción a los derechos de autor, podría argumentarse entonces que no podría afectarle la prohibición de antielusión (Grunewaldt, 20I I: I I) y los usuarios podrían eludir medidas tecnológicas de protección con miras a ejercer los derechos que entrega el agotamiento, sin que ello signifique una infracción a la DMCA. Sin embargo, no hay claridad respecto al alcance de la expresión «defenses to copyright infringement» y, en virtud de ello, algunos argumentan que esta expresión tendría un alcance restringido, en cuanto estas «defensas» serían aquellas contempladas expresamente en la ley y el agotamiento del derecho no estaría dentro de ellas (Grunewaldt, 20I I: I I). De todas maneras, es una norma cuya interpretación es discutible y, en tal sentido, podría constituir una posible salida con miras a atenuar el efecto de la Sección I 20 I y, en general, equilibrar la regulación ofrecida por esta ley.

Por último, debemos analizar el tema del derecho de reproducción. Aquí incluiremos tanto el problema relacionado con las copias RAM, como el problema de la facilidad de infracción a este derecho de reproducción. En términos generales, nos parece que el principal problema en torno a cómo se articula este impedimento es el extremo tecnicismo o, en otras palabras, la falta de sensatez con que se aborda el tema de las reproducciones, en especial el tema de las copias RAM. Si seguimos la doctrina de las copias RAM, terminaríamos llegando al extremo de no poder desarrollar prácticamente ningún acto en la red digital, sin que ello se tradujera en una infracción al derecho de reproducción. Por ejemplo, si quisiéramos revisar el material fotográfico de un artista, aun cuando este material se encontrara en la propia página web del artista entendemos que fueron subidas con su consentimiento- $-\mathrm{y}$ hubieran sido subidas con el fin de que el público pudiera verlas, la verdad es que no podría cumplirse este objetivo sin infringir el derecho de reproducción. Más aún, si queremos desarrollar una compra por internet, es imposible llevarla a cabo sin hacer al menos una copia RAM del archivo.

que se favorece de sobremanera al titular del derecho en desmedro de los consumidores. 
Por lo tanto, nos parece necesario abordar este tema con un mayor grado de flexibilidad, en el sentido de tener claridad respecto de cuáles reproducciones constituyen una infracción al derecho de autor, y cuáles reproducciones son hechas con un mero fin instrumental, en vistas a cumplir un fin diferente, y legítimo, autorizado por el sistema de derechos de autor.

Una buena manera de hacer esta distinción podría ser pensar de qué manera un acto de reproducción afecta los intereses del titular del derecho. Entendemos que este derecho de autor — derecho insigne dentro del grupo de los derechos patrimoniales- es reconocido con el fin de asegurar una retribución económica al titular del derecho. Por lo tanto, podemos afirmar que los actos de reproducción constituirán una infracción a los derechos de autor en la medida en que tal reproducción impida al titular obtener ingresos económicos por la explotación de la obra.

Bajo tal criterio, revisemos los principales actos de reproducción que debe enfrentar un usuario en virtud de ejercer los beneficios entregados por el agotamiento del derecho, para determinar cuándo estaríamos frente a una infracción y cuándo podríamos estar frente a un uso permitido.

En primer lugar, las copias RAM. Sabemos que el carácter esencial de este tipo de copias es su carácter volátil, temporal y, más aún, instrumental. Estas copias se crean en la memoria RAM del computador con el fin de llevar a cabo las diversas tareas que ordenamos que haga al computador, y en la medida en que el computador va desarrollando estas tareas, las copias reproducidas en la memoria RAM se irán borrando automáticamente. El usuario ni siquiera puede disponer de este tipo de obras pues, por esencia, están destinadas a desaparecer al ser eliminadas de la memoria que las contiene. En tal sentido, es difícil pensar cómo este tipo de reproducciones podría afectar el derecho del titular, en cuanto no constituye un desmedro económico. Más aún, en el contexto de una compra llevada a cabo por internet, por ejemplo en iTunes, el titular del derecho necesariamente debe recurrir a las copias RAM para llevar a cabo su compra. Se estarían generando más reproducciones de aquella por la cual estaría pagando el usuario; sin embargo, se entiende que estas reproducciones son realizadas con el fin último de llevar a cabo la compra del archivo multimedia y, por lo tanto, no tiene por qué constituir una infracción a los derechos de autor.

Distinto es el caso de las reproducciones hechas en el contexto de una 
venta de un archivo multimedia por parte de un usuario. En este caso, recordemos, el usuario que quiere revender su archivo no está vendiendo su archivo propiamente tal, sino que está revendiendo la copia de su copia. En tal sentido, decimos que es distinto al caso de las copias RAM en cuanto hay un riesgo mucho mayor de infracción a los derechos de autor.

Sin embargo, en la medida en que el usuario que revende su archivo elimine de su disco duro todo registro del archivo que acaba de vender, no debiera haber impedimento de que las reproducciones llevadas a cabo en este contexto sean legítimas. En la medida en que el usuario que revendió su archivo no mantenga una copia del mismo, y en virtud de ello no pueda seguir revendiendo el archivo todas las veces que quiera, no tendría por qué haber una infracción a los derechos de autor, ${ }^{33}$ en cuanto el interés económico del titular estaría a salvo: habría obtenido una retribución económica por la venta del archivo al primer usuario, y éste no constituiría una competencia ilegal en el sentido de vender múltiples reproducciones del archivo por el cual pagó sólo una vez. Tal escenario es similar al que se desenvuelve la teoría del agotamiento en un medio tangible, y, en virtud de ello, no debieran existir impedimentos para una implementación similar en los medios tecnológicos.

Los titulares de derecho argumentan que los usuarios tienen todas las facilidades para infringir el derecho de reproducción y revender sin restricciones el archivo adquirido legalmente. Sin embargo, no puede partirse de la base de que el usuario va a infringir los derechos de autor con el fin de evitar la implementación de la teoría del agotamiento. ${ }^{34}$ Además, existen diversas medidas que podrían implementarse con miras a fomentar el respeto de estos derechos por parte de los usuarios: desde medidas tecnológicas que eliminen automáticamente el archivo una vez que este haya sido revendido — «forward-and-delete technolo-

33. En el caso UsedSoft $v$. Oracle, el tribunal reconoce esta opción, al afirmar que el usuario puede revender su copia del software, pero para que no viole el derecho de reproducción debe dejarla inutilizable, una vez hecha la transacción (apartados 70, 78 80, Tribunal de Justicia de la Unión Europea, USedSoft v. Oracle).

34. Diversa jurisprudencia estadounidense recoge este criterio, en el sentido de que no se puede presumir a priori que los consumidores van a infringir los derechos de autor. Véase Supreme Court of the United States, 2006, Ebay, Inc. v. MercExchange. 
gy»-, hasta medidas tan simples como que el usuario que ha revendido el archivo tenga la carga de la prueba de la legalidad de la acción realizada. En la medida en que los usuarios que han revendido los archivos tengan la carga de probar que no han dejado copias del archivo en su disco duro ni en algún dispositivo, ellos mismos procurarán desarrollar la reventa conforme a la ley - entendemos, sin guardar una copia del archivo revendido-y procurar tener los medios probatorios que avalen esta práctica.

Por lo tanto, el derecho de reproducción no debiera constituir un impedimento indiscriminado a la implementación del agotamiento del derecho en internet. Su aplicación en redes digitales es posible, sin que ello implique una infracción al sistema de derechos de autor.

Por último, nos gustaría mencionar la norma de la Sección i 77 de la I976 Copyright Act. Como vimos antes, esta norma consagra la limitación de ciertos derechos exclusivos respecto del uso de los programas de computador. En particular, garantiza a los usuarios de una copia de un programa de computador el derecho de reproducir, adaptar y redistribuir estas copias (Perzanowski y Schulz, 2010: 922).

Esta norma lo que hace es reconocer que los usuarios requieren muchas veces llevar a cabo acciones que podrían resultar en una infracción al derecho de autor, con el fin de utilizar la copia de su programa de manera satisfactoria. Y en la medida en que tales «infracciones» son llevadas a cabo no con el fin de menoscabar los intereses del titular, sino que con el fin de hacer un uso satisfactorio de su copia, es que tales actos no deben ser considerados infracciones en sentido estricto, sino que, al contrario, deben ser permitidos con el fin de que los usuarios puedan gozar del uso de sus copias libremente, sin que tal práctica pueda significar un acto ilegal.

Una norma de alcance general con el criterio aplicado en la Sección I I7, sería un gran avance en la adaptación del sistema de derechos de autor en un medio tecnológico, y recogería todo lo antes dicho respecto de las reproducciones y su uso instrumental, en cuanto este tipo de acciones no deben constituir una infracción a los derechos de autor.

El razonamiento presente en esta norma se desprende del denominado principio de agotamiento del derecho. Este principio, en términos simples, plantea que la teoría del agotamiento del derecho de distribución se enmarca dentro de un principio de más amplio alcance de 
agotamiento (Perzanowski y Schulz, 2010: 904), de acuerdo al cual los usuarios deben estar autorizados para reproducir o incluso hacer obras derivativas de la copia de la obra que les pertenece, con el fin de permitirles el uso, preservación o alienación de su copia legalmente adquirida (Perzanowski y Schulz, 2010: 939-940).

Este principio ha sido desarrollado por el common law desde antes incluso que el caso Bobbs-Merrills Company v. Strauss, que dio inicio a la teoría del agotamiento del derecho de distribución (Perzanowski y Schulz, 2010: 907-908).

La diversa jurisprudencia que recogió este principio permitió, en definitiva, mirar en los propósitos básicos de la protección del derecho de autor la necesidad de equilibrar los intereses de los titulares de derecho de autor y el público, y se revisaron los hechos concretos buscando abordar los vacíos presentes en el sistema legal de derechos de autor, y aliviar la tensión existente entre los incentivos a la creación y el acceso y goce de las obras intelectuales (Perzanowski y Schulz, 2010: 930-93I).

Un razonamiento como el presentado en el principio del agotamiento del derecho, por lo tanto, es necesario para la preservación de los derechos de los usuarios respecto de sus copias, en un mercado digital (Perzanowski y Schulz, 2010: 905). Su razonamiento se recoge en normas como las de la Sección i i7. Sin embargo, además de ello, es fundamental para el desarrollo y aplicación correcta de este principio el estudio de los hechos concretos, esto es, el caso a caso. La línea divisoria entre lo que constituye un acto infractor de derecho de autor y un acto legítimo puede ser muchas veces difícil de identificar. Es por ello que la jurisprudencia debe jugar un rol fundamental en el desarrollo y preservación de esta doctrina y, más aún, del enfoque que propone respecto a cómo abordar la protección de los derechos de autor. Un enfoque con estas características constituye una posición adecuada para abordar el desafío de adaptar e implementar la doctrina de la primera venta en un entorno digital.

\section{LOS CASOS DE BOPABOO Y REDIGI}

Antes de terminar, nos gustaría mencionar dos casos que han intentado llevar a la práctica la teoría del agotamiento en internet, a través de la creación de mercados secundarios de archivos de mp3. Son los casos de Bopaboo y Redigi. 
Bopaboo fue la primera compañía que intentó abiertamente implementar una plataforma donde se pudiera revender música en formato $\mathrm{mp}_{3}$, ofreciendo un método legal que permitiera a las personas vender sus archivos usados de música, y comprar archivos de música libres de DRM (Digital Rights Management) (Grunewaldt, 20II: 6). Las condiciones de uso que impuso a los usuarios, además del registro en la página, es que el archivo haya sido adquirido legalmente, y que éste sea eliminado una vez realizada la reventa. Bopaboo fue inaugurado el año 2008, y planeaba entrar en funcionamiento para el año 2009, sin embargo, sus creadores decidieron posponer de manera indefinida su puesta en marcha (Grunewaldt, 20II: 7).

Pese a que finalmente este servicio no entró en funcionamiento —ni existe claridad respecto a si lo hará en un futuro cercano-, destacamos esta iniciativa, en cuanto fue la primera propuesta formal, conocida, en que se intentó implementar un mercado secundario en redes digitales, tratando de rescatar un beneficio obtenido gracias a la teoría del agotamiento, que corría riesgo de perderse en un entorno digital.

Otro caso de este tipo lo constituye Redigi. Esta compañía, que comenzó a funcionar en el año 20II, se autodefine como "The World's First Pre-Owned Digital Marketplace». De acuerdo a lo establecido en los términos legales en su página web, Redigi ofrece un servicio legal que permite comprar y vender archivos de música. Este servicio se sustenta gracias a un software que cuenta con la tecnología suficiente para asegurar que las copias que ingresan a este mercado sean legalmente adquiridas - the Verification Engine-, a la vez que asegura que toda la música que el usuario introduce al sistema de Redigi sea removida del disco duro - the Cloud-, con lo cual se asegura que la única copia existente sea la original. Tal cual lo afirma en sus términos legales, el mercado que ofrece Redigi se sustenta legalmente gracias a la existencia de la doctrina de la primera venta.

Sin embargo, en enero del año 2012 la empresa fue demandada por Capitol Records, bajo el argumento de que el servicio prestado por Redigi contribuía a la infracción a los derechos de autor. El caso se resolvió el año siguiente con decisión favorable para Capitol Records. El tribunal estadounidense falló argumentando que el sitio de internet no vende productos usados, sino que comercializa copias ilegales, reproducciones no autorizadas de los archivos digitales. 
El funcionamiento y éxito de Redigi aún es incierto. Pese al fallo desfavorable, mantendremos dudas respecto de si la iniciativa podrá seguir su curso. Fundamos esta incertidumbre en que la empresa cuenta con otros resquicios legales para insistir en el desarrollo del proyecto. ${ }^{35}$

Sin embargo, desde ya podemos considerarla un éxito, en cuanto se articula como un mercado secundario legal, el cual ofrece una tecnología que podría asegurar la legalidad de su desarrollo. Propuestas de este tipo, junto con tecnologías que avancen en este sentido, podrán ayudar al desarrollo de un mejor sistema de protección a los derechos de autor.

\section{CONCLUSIONES}

A lo largo de esta investigación hemos reflexionado en torno a la posibilidad de implementar el agotamiento del derecho en un entorno digital. En primer lugar, debemos reconocer que las condiciones actuales de aplicación son difíciles. La regulación en torno al derecho de autor se encuentra aún en proceso de adaptación a las nuevas tecnologías y, si bien existen tratados y legislaciones que responden a esta problemática, falta aún trabajo por hacer. A su vez, con la incorporación de temas como las licencias y las medidas tecnológicas ineludibles, el análisis de esta materia se ha vuelto más complejo. Pero pese a todos estos obstáculos, nos parece que la respuesta es bastante simple: el agotamiento del derecho en internet es posible.

Creemos que el trabajo jurisprudencial y doctrinal también puede y debe cumplir un rol clave en la adaptación del agotamiento del derecho en los nuevos requerimientos tecnológicos. Con miras a este objetivo, creemos que la celebración de tratados con otros países en materia de derecho de autor será positivo en la medida en que fomente la discusión y la reflexión en torno al tema, ejercicio necesario para evitar caer en el estancamiento y desactualización. Sin embargo, hay que procurar que tales acuerdos vayan en la dirección correcta, esto es, que respondan a una reflexión sensata en torno a cómo adaptar el derecho de autor a las nuevas tecnologías.

35. "Un tribunal de EEUU prohíbe la reventa de música digital», El Mundo, 2 de abril de 20I3, disponible en http://www.elmundo.es/elmundo/2013/04/02/ navegante/1364882898.html. 
En otras palabras, es necesario adoptar y masificar un sistema de derecho de autor más flexible. En tal sentido, nos parece que la propuesta que ofrece el principio del agotamiento del derecho, que ya ha sido adoptado en alguna normativa, como la Sección II 7 de la Copyright Act, es la mejor solución para lograr una plena implementación de la doctrina de la primera venta en las redes digitales, con miras a un pleno ejercicio tanto de los derechos de autor, como de los derechos a acceder a las obras protegidas por él.

En esta línea, reiteramos que corresponde a la jurisprudencia jugar un rol clave en la aplicación de la teoría, en cuanto el estudio del caso concreto es fundamental para determinar qué usos pueden ser permitidos y cuáles no. Los tribunales de justicia deben asegurar los estándares básicos de protección sin perderse en tecnicismos y respetando los principios básicos que rigen este sistema. En el contexto actual, la jurisprudencia es la mejor herramienta para aplicar razonablemente el derecho de autor a las nuevas tecnologías, independiente del rol que debe jugar la legislación y los cuerpos normativos en general.

Casos como los de Bopaboo y Redigi demuestran que es posible implementar una teoría del agotamiento en medios digitales. En tal sentido, esperamos que como éstas, surjan muchas nuevas iniciativas con miras a reafirmar el efecto de la doctrina de la primera venta en internet, que siga protegiendo el mayor y más fácil acceso a la cultura.

Entendemos que internet es un modo diferente de concebir la relación entre los autores y su audiencia. Nunca antes en la historia habíamos tenido tan fácil acceso a tanta cultura. Debemos aprender a valorar y aprovechar estos beneficios, a través de una regulación que respete esta riqueza. El derecho de autor debe seguir siendo un instrumento en función de la sociedad que, como afirma Lawrence Lessig, permanezca en una posición subordinada con respeto al valor de la creatividad (Lessig, 2005: 30).

La reflexión en torno a un derecho de autor en internet es una discusión que se está llevando a cabo a nivel doctrinal, legal y jurisprudencial. En tal sentido, podemos ser optimistas en que nuevas propuestas seguirán madurando, y, con el tiempo, una visión más razonable en torno a la regulación del derecho de autor se seguirá desarrollando. 


\section{REFERENCIAS}

Álvarez, Carmen Paz (2006). «Importaciones paralelas y agotamiento de derechos en la jurisprudencia chilena». En Marcos Morales (coord.), Temas actuales de propiedad intelectual. Santiago: LexisNexis.

Antequera, Ricardo (2005). «Las limitaciones y excepciones al derecho de autor y los derechos conexos en el entorno digital». XI Curso Académico Regional OMPI/SGAE sobre Derecho de Autor y Derechos Conexos para países de América Latina: El derecho de autor y los derechos conexos en el entorno digital, Documento OMPI-SGAE/ DA/ASU/05/2, 26 de octubre de 2005. Disponible en http://www. wipo.int/edocs/mdocs/lac/es/ompi_sgae_da_asu_05/ompi_sgae_da_ asu_05_2.pdf.

ARL [Asociaciones de Bibliotecas de Estados Unidos] (2002). «El agotamiento de los derechos y la doctrina de la primera venta en el entorno digital». Boletín de Derecho de Autor, 36 (4): 19-36. Disponible en http://unesdoc.unesco.org/images/0013/001397/139700S.pdf.

Bonadio, Enrico (20II). "Parallel Imports in a Global Market: Should a Generalised International Exhaustion Be the Bext Step». European Intellectual Property Review, 33 (3): I53-I6I. Disponible en http:// ssrn.com/abstract $=1762900$.

Carver, Brian (20II). «Why License Agreements Do Not Control Copy Ownership: First Sales and Essential Copies». Berkeley Technology Law Journal, 25 (4): I887-I954. Disponible en http://scholarship. law.berkeley.edu/btlj/vol25/iss4/7/.

Castro, Juan (2009). «El agotamiento de los derechos de propiedad intelectual». Revista La Propiedad Inmaterial, I 3: 253-82.

Cerda, Alberto (20II). "Armonización de los derechos de autor en la Comunidad Andina: Hacia un nuevo régimen común». Ius et Praxis, I7 (2): 23I-282. Disponible en http://www.scielo.cl/pdf/iusetp/ v17n2/art09.pdf.

Cohen, Julie (I995). «A Right to Read Anonymously: A Closer Look at «Copyright Management» in Cyberspace». Connecticut Law Review, 28: 98 I-I039.

Davis, Nakimuli (2009). «Reselling Digital Music: Is There a Digital First Sale Doctrine». Loyola of Los Angeles Entertainment Law Review, 29 (3): 363-373. 
Erdozain, Jóse Carlos (2002). Derechos de autor y propiedad intelectual en Internet. Madrid: Tecnos.

Even, Yonatan (2008). «Appropriability, First Sale \& Exhaustion». Septiembre 2008. Disponible en http://ssrn.com/abstract=1274822.

Fernández, Carlos (2005). «El derecho de autor en el ámbito digital. Tratados internet». III Jornada de Derecho de autor en el mundo Editorial, Buenos Aires 2I y 22 de abril de 2005, Centro de Administración de Derechos Reprográficos, Fundación El Libro, OMPI, Centro Español de Derechos Reprográficos, Centro Regional para el Fomento del Libro en América Latina y el Caribe y Federación Internacional de Organizaciones de Derechos Reprográficos, Secretaría de Política Judicial y Asuntos Legislativos del Ministerio de Justicia y Derechos Humanos de la Nación Argentina. Disponible en http://www.wipo.int/ edocs/mdocs/lac/es/ompi_da_bue_2_05/ompi_da_bue_2_05_1.pdf.

Ficsor, Mihály (2003). Guía de los tratados de derecho de autor y derechos conexos administrados por la OMPI. Ginebra: OMPI. Disponible en http://bit.ly/1IbnGEa.

Gasser, Urs, Derek Bambauer, Andrew Bragin, Jacqueline Harlow, Charles Hoffmann, Renny Hwang, Joseph Jackson, Georg Krog, Edward Locke, Stephen Mohr, Ivan Reidel, Derek Slater, C. Lee Wilson, John Palfrey y William Fisher (2004). «Itunes. How Copyright, Contract, and Technology Shape the Business of Digital Media. A case study». Berkman Center for Internet \& Society at Harvard Law School Research Publication (2004-07). Disponible en http://cyber.law.harvard.edu/media/uploads/53/GreenPaperiTunes041004.pdf. Gaubiac, Yves (2002). «El agotamiento de los derechos en el entorno analógico y digital». Boletín de Derecho de Autor, 36 (4): 2-I 8. Disponible en http://unesdoc.unesco.org/images/0013/001397/139700S.pdf.

Grunewaldt, Andrés (20I I). «First Sale Doctrine and Resale of Digital Music: Is it Legally Possible?» Inédito en poder de la autora.

LESSIG, Lawrence (2005). Cultura libre: Cómo los grandes medios usan la tecnología y las leyes para encerrar la cultura y controlar la creatividad. Santiago: Lom.

Martin-Prat, María (2004). «Aplicación del derecho de autor en el contexto de las redes digitales». En Eduardo Carrasco (ed.), Derecho de autor: Un desafío para la creación y el desarrollo. Santiago: Lom y Consejo Nacional de la Cultura y las Artes. 
Muñoz, Santiago (2000). La regulación de la red. Poder y Derecho en Internet. Barcelona: Taurus.

Organización Mundial de Propiedad Intelectual, OMPI (i999). «Protección internacional del derecho de autor.» Documento preparado por Oficina Internacional de la OMPI. Disponible en http:// www.wipo.int/copyright/es/activities/pdf/international_protection. pdf.

-. (I996). "Tratado de la OMPI sobre Derechos de Autor y Tratado de la OMPI sobre Interpretación o Ejecución y Fonogramas», Documento preparado por Oficina Internacional de la OMPI. Disponible en http://documentostics.com/documentos/tratados_OMPI.pdf.

Perzanowski, Aaron (2009). "Fixing RAM Copies». Northwestern University Law Review, IO4 (3): 547-589. Disponible en http://ssrn. com/abstract $=1441685$.

Perzanowski, Aaron y Jason Schulz (2010). «Digital Exhaustion». University of California Los Angeles Law Review, 58 (4): 889-946. Disponible en http://www.uclalawreview.org/pdf/58-4-1.pdf.

REeSe, Anthony (200I). "The public display right: the copyright act's neglected solution to the controversy over «RAM copies»». University of Illinois Law Review, I: 83-I 50. Disponible en http://www.law. uci.edu/faculty/full-time/reese/reese_illinois.pdf.

-. (2003). «The first sale doctrine in the era of digital networks». Boston College Law Review, 44 (2): 577-652. Disponible en http://lawdigitalcommons.bc.edu/cgi/viewcontent.cgi article $=2233 \&$ context $=$ bclr.

Rengifo, Ernesto (1997). Propiedad intelectual: El moderno derecho de autor. Segunda edición. Bogotá: Universidad Externado de Colombia.

United State Copyright Office (200I) «DMCA Section io4 Report». Disponible en http://www.copyright.gov/reports/studies/dmca/ sec-104-report-vol-1.pdf.

\section{SOBRE LA AUTORA}

Javiera Plana Perillán es abogada. Licenciada en Ciencias Jurídicas y Sociales por la Universidad de Chile. Su dirección de correo electrónico es javiera.plana.p@gmail.com.

Este trabajo fue recibido el 28 de junio y aprobado el 22 de julio de 2016. 
